\title{
Flow transition criteria of a liquid jet into a liquid pool
}

\author{
Shimpei Saito ${ }^{\mathrm{a}, *}$, Yutaka Abe ${ }^{\mathrm{b}}$, Kazuya Koyama ${ }^{\mathrm{c}}$

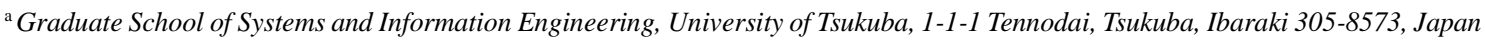 \\ ${ }^{\mathrm{b}}$ Faculty of Engineering, Information and Systems, University of Tsukuba, 1-1-1 Tennodai, Tsukuba, Ibaraki 305-8573, Japan \\ ' Reactor Core and Safety Design Department, Mitsubishi FBR Systems, Inc., 2-34-17 Jingumae, Shibuya, Tokyo 150-0001, Japan
}

Keywords: sodium-cooled fast reactor, core disruptive accident, melt coolant interactions, jet breakup, droplet formation, liquid-liquid systems, breakup regime

\begin{abstract}
To better understand the fundamental interactions between melt jet and coolant during a coredisruptive accident at a sodium-cooled fast reactor, the jet breakup and droplet formation in immiscible liquid-liquid systems were studied experimentally. Experiments using two different pairs of test fluids were carried out at isothermal conditions. The observed jet breakup behavior was classified into characteristic regimes based on the classical Ohnesorge classification in liquid-gas systems. The variation in breakup length obtained in the present liquid-liquid system was similar to that in a liquidgas system. The droplet size distribution in each breakup regime was analyzed using image processing and droplet formation via pinch-off, satellite formation, and entrainment was observed. The measured droplet size was compared with those available from melt jet experiments. Based on the observation and analysis results, the breakup regimes were organized on a dimensionless operating diagram, with the derived correlations representing the criteria for regime boundaries of a liquid-liquid system. Finally, the experimental data were extrapolated to the expected conditions of a sodium-cooled fast reactor. From this, it was implied that most of the hydrodynamic conditions during an accident would be close to the atomization regime, in which entrainment is the dominant process for droplet formation.
\end{abstract}

\section{Nomenclature}

d droplet diameter

$D_{j 0} \quad$ nozzle diameter

$\mathrm{Fr} \quad$ Froude number

L breakup length

n number of droplets

Oh Ohnesorge number

\footnotetext{
${ }^{*}$ Corresponding author. Tel.: +81 298535487.

E-mail addresses: s1630195@u.tsukuba.ac.jp (S. Saito)
} 


$$
\begin{array}{ll}
R e & \text { Reynolds number } \\
u_{j 0} & \text { jet velocity } \\
u_{s} & \text { settling velocity } \\
W e & \text { Weber number }
\end{array}
$$
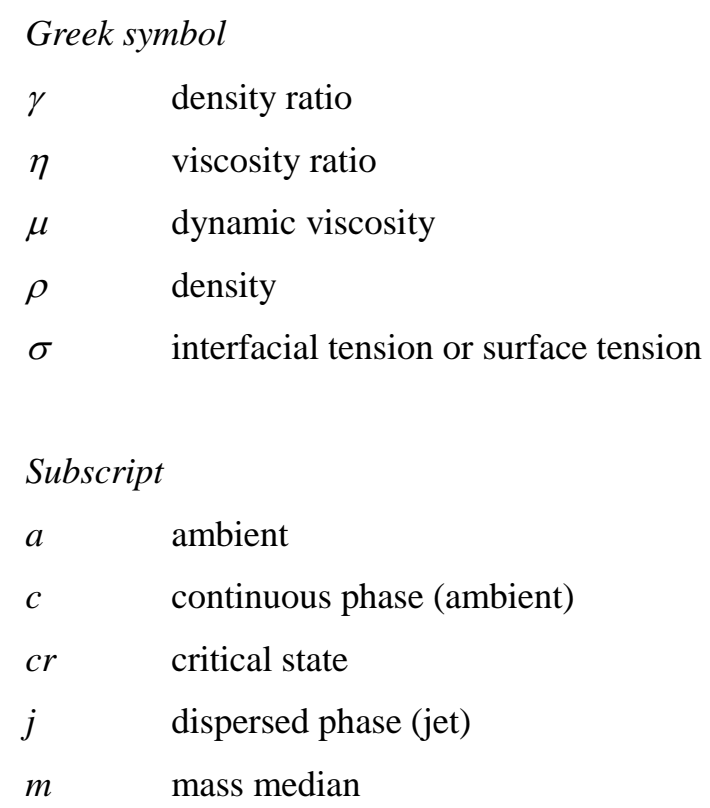

\section{Introduction}

The next generation of nuclear reactors is likely to include sodium-cooled fast reactors (SFRs), which are designed to shut down passively and non-energetically in the event of a core-disruptive accident (CDA) (Suzuki et al., 2014a). Even if the event is non-energetic, a considerable amount of the fuel may melt in the core region. Therefore, it is essential that this core material can be held in the reactor vessel for a long time after it has solidified and cooled sufficiently. In other words, postaccident heat removal (PAHR) must be part of the safety assessment. Fig. 1 depicts a possible CDA scenario in which the molten core material enters the coolant as melt jets. It is therefore particularly important in PAHR to be able to estimate and evaluate the behavior known as jet breakup or fragmentation in the coolant. A fair amount of coolant (liquid sodium) could remain during a CDA in an SFR, unlike a loss-of-coolant accident in a light-water reactor. Qualitatively, the melt jets in an SFR accident are considered to fragment, of which would prevent the reactor structure from being attacked by concentrated jets, as well as helping the generated debris to cool down more quickly. 


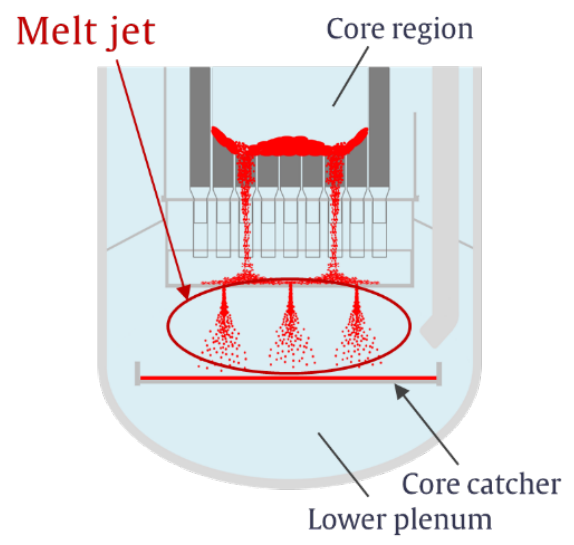

Fig. 1. Concept of a core-disruptive accident in an SFR

However, it would be very difficult to investigate the breakup of a melt jet directly in an SFR using actual materials. Instead, a scoping study of the fundamental process is an effective approach to understanding the actual situation. To date, there have been many experimental efforts under various conditions that have been aimed at clarifying the melt-coolant interaction, including $\mathrm{UO}_{2}$ into sodium (Magallon et al., 1992; Schins and Gunnerson, 1986), molten oxide into sodium (Kaiser et al., 1998; Matsuba et al., 2015; Schins and Gunnerson, 1986), molten metal into sodium (Kaiser et al., 1998; Matsuba et al., 2016a; Nishimura et al., 2010; Schins and Gunnerson, 1986), corium into water (Huhtiniemi and Magallon, 2001; Magallon, 2006; Magallon and Huhtiniemi, 2001; Spencer et al., 1994), molten oxide into water (Kaiser et al., 2001; Karbojian et al., 2009; Kudinov et al., 2013; Manickam et al., 2014, 2016; Moriyama et al., 2005) and molten metal into water (Abe et al., 2006; Bang et al., 2003; Bang and Kim, 2014; Bürger et al., 1995; Cho et al., 1991; Dinh et al., 1999; Iwasawa et al., 2015b, 2015c; Kondo et al., 1995; Mathai et al., 2015; Matsuo et al., 2008; Pillai et al., 2016; Spencer et al., 1986; Wei et al., 2016). The aim of all these experiments and tests was not limited to understanding a CDA in an SFR; a severe accident in a light-water reactor was also included as a possible scenario.

In the context of FARO/TERMOS, Magallon et al. (1992) performed two experiments that involved pouring $100 \mathrm{~kg}$-scale molten $\mathrm{UO}_{2}$ into sodium. These experiments are often referenced as $\mathrm{T} 1$ and $\mathrm{T} 2$. Part of the debris was collected to analyze the size distribution of particles that settled in the test section. The evaluated particle sizes were in the range of $10^{1}-10^{3} \mu \mathrm{m}$. The penetration distance of the melt was estimated to be as much $1 \mathrm{~m}$, whereas the released diameters were $50 \mathrm{~mm}$ (T1) and $80 \mathrm{~mm}$ (T2). Suzuki et al. (2014a) pointed out that the distance was much smaller than that predicted by the Saito correlation (Saito et al., 1988) [see Fig. 22 in Suzuki et al. (2014a)]. Recently, Matsuba et al. carried out experiments involving molten aluminum (Al) into sodium (Matsuba et al., 2016a) and molten alumina $\left(\mathrm{Al}_{2} \mathrm{O}_{3}\right)$ into sodium (Matsuba et al., 2016b). Although the debris that settled onto the bottom 
of the test section could be collected after the experiments, it was difficult to visualize and observe the jet breakup process in detail.

During the interactions between melt jet and coolant, thermal interactions (e.g., surface freezing or coolant-vaporization) and hydrodynamic interactions (e.g., interfacial instability between two fluids, such as Kelvin-Helmholtz/Rayleigh-Taylor instabilities, and liquid entrainment or stripping from the interface) are considered to occur simultaneously. In an SFR accident, there may be no significant vapor film on the jet surface (Kondo et al., 1995; Suzuki et al., 2014a), thus it is important to investigate the jet breakup behavior under the condition of liquid-liquid direct contact. Separate investigations of these thermal and hydrodynamic interactions would help to further understand the fundamental processes of jet breakup. Hence, a number of experimental studies have focused on the hydrodynamic interactions by using various test fluids in immiscible liquid-liquid systems (Abe et al., 2007; Dinh et al., 1999; Kuroda et al., 2012; R. Saito et al., 2014, 2016; S. Saito et al., 2014a; 2016b). Recently, the literature has been supplemented by numerical studies on jet breakup in immiscible liquid-liquid systems by using the volume-of-fluid method (Thakre et al., 2015), the advanced interface tracking method (Suzuki et al., 2014b), and the lattice Boltzmann method (Iwasawa et al., 2015a; Matsuo et al., 2015; S. Saito et al., 2016a).

As mentioned above, the hydrodynamic interaction is considered to be an important factor in meltjet breakup. Nishimura et al. (2010) suggested a hydrodynamic fragmentation model that agreed well with their copper/sodium experiments at high ambient Weber numbers (> 200). The ambient Weber number,

$$
W e_{a}=\frac{\rho_{c} u_{j 0}^{2} D_{j 0}}{\sigma}
$$

is often used to characterize the jet breakup length (Bürger et al., 1995; Ginsberg, 1985; Thakre et al., 2015) and the diameters of the resulting fragments (Matsuba et al., 2016b; Nishimura et al., 2010). Matsuo et al. (2008) concluded from their melt-water experimental data that the dominant effect on jet breakup was the shear force that acted on the interface. They further concluded that, in such shearforce-dominated conditions, the Epstein-Fauske correlation (Epstein and Fauske, 2001) could be used to predict the jet breakup length. The key aspect of the Epstein-Fauske correlation is the assumption of entrainment on the basis of the Kelvin-Helmholtz instability. Epstein and Fauske (2001) indicates that their correlation agreed well with the previous data on breakup length, which are considered to be in the atomized state. The conditions for the appearance of atomized breakup in liquid-liquid systems is an issue that is yet to be clarified. Identifying those conditions would enables us to use a simplified physical model to predict breakup length and fragment diameter and hence be able to evaluate melt coolability (e.g., Abe et al., 2005, 2006).

The breakup of a liquid jet into droplets is itself an important phenomenon in natural and industrial processes, so the instability of liquid jets has been studied extensively [see the comprehensive reviews 
by Eggers and Villermaux (2008), Lin and Reitz (1998), and McCarthy and Molloy (1974)]. Based on his experimental observation, Ohnesorge (1936) showed that liquid jets generally falling into one of four regimes (Kolev, 2005; McKinley and Renardy, 2011):

(0) Slow dripping from the nozzle under gravity with no formation of a jet (dripping regime),

(I) Breakup of a cylindrical jet by axisymmetric perturbations of the surface (varicose regime),

(II) Breakup by screw-like perturbations of the jet (sinuous regime),

(III) Atomization of the jet (atomization regime).

Furthermore, he expressed the criteria for the breakup regimes I-III qualitatively on a dimensionless operating diagram [see Fig. 1 in Ohnesorge (1936) or Fig. 4 in McKinley and Renardy (2011)]. According to his article, the appropriate dimensionless groups are the Ohnesorge number $\mathrm{Oh}$ and the Reynolds number $R e$ based on the dispersed phase:

$$
\begin{gathered}
O h=\frac{\mu_{j}}{\sqrt{\rho_{j} \sigma D_{j 0}}}, \\
R e=\frac{\rho_{j} u_{j 0} D_{j 0}}{\mu_{j}} .
\end{gathered}
$$

The operating diagram considers the inertia, viscous, and interfacial forces of a liquid jet. The boundaries of each regime can be described in following functional form:

$$
O h=a R e^{b} \text { or } R e=a O h^{b},
$$

where $a$ and $b$ are arbitrary constants that are generally determined by fitting from experimental data. Based on Ohnesorge's experimental data, Kolev (2005) later provided a quantitative expression for the functional form of the boundaries between regimes I-III:

$$
\begin{array}{r}
R e=46 O h^{-4 / 5} \text { (between (I) and (II)), } \\
R e=270 O h^{-4 / 5} \text { (between (II) and (III)), }
\end{array}
$$

Note that the coefficient values in Eqs. (5) and (6) are simply fitting values; it remains to identify the physical meaning of the constants (Kolev, 2015). Using the aforementioned functional forms, the jet breakup regimes can be estimated approximately. Functional forms similar to Eqs. (5) and (6) have been proposed elsewhere (Grant and Middleman, 1966; Merrington and Richardson, 1947; Tanasawa and Toyoda, 1954).

Liquid-liquid jet dynamics occur in fields such as chemical engineering (Das, 1997; Kitamura et al., 1982; Meister and Scheele, 1969a, 1969b, Takahashi and Kitamura, 1972, 1971) and ocean engineering (Riestenberg et al., 2004; Tang and Masutani, 2003). Experiments using a characteristic of liquid-liquid systems known as refractive index matching have also been reported to further understand jet breakup dynamics (Longmire et al., 2001; Milosevic and Longmire, 2002; S. Saito et al., 2014b; Saito et al., 2015b). Takahashi and Kitamura (1971) observed jet breakup in liquid-liquid systems using various combinations of test fluids and focusing on jets in the laminar state. Riestenberg 
et al. (2004) injected water into liquid $\mathrm{CO}_{2}$ and classified the data into three regimes similar to those of Ohnesorge (1936). While studies on liquid-liquid systems such as those discussed above provide significant insights into the jet breakup regimes, most have been limited to dripping or laminar flows; there have been fewer studies on the transition from dripping to atomization in liquid-liquid systems.

In this study, we carried out jet injection experiments using test fluids to investigate the dynamics of jet breakup and droplet formation in immiscible liquid-liquid systems as a fundamental process of melt-jet-coolant interactions. The rest of the article is organized as follows. In Section 2, the experimental method and conditions are presented. The image processing procedure for droplet size analysis is also given in this section. In Section 3, the experimental results and discussion are provided. The breakup regimes observed in the present experiments are classified and discussed in the context of breakup length and droplet size distribution. The evaluated droplet diameters are compared with those from available melt-jet experiments. Finally, the breakup regime under conditions of an SFR accident is considered by extrapolation from the experimental data. Section $\mathbf{4}$ concludes this article.

\section{Experimental method}

\subsection{Experimental apparatus}

Fig. 2 is a schematic diagram of the experimental apparatus, consisting of a test section, a light source and a high-speed video camera. A test fluid for the dispersed phase was injected into an acrylic reservoir $(200 \times 200 \times 450 \mathrm{~mm})$ that was filled with a second test fluid for the continuous phase. The dispersed-phase fluid was kept at a constant hydraulic head in an overflow tank, as shown in Fig. 2, thus forming a steady-state jet flow in the test section. The injection velocity was adjusted by changing the opening ratio of a needle valve. We employed four types of cylindrical nozzle with inner diameter $D_{j 0}=3,5,7$, and $10 \mathrm{~mm}$. A high-speed video camera (FASTCAM mini UX100, Photron) was installed to record the flow images of the jet interface. The high-speed visualization was performed at 500 4,000 fps with a shutter speed of $0.000125-0.00025$ s depending on the injection conditions. The image resolution of image was $512 \times 1024$ pixels. A metal halide lamp (HVS-SL, Photron) was placed at the opposite side of the test section to the high-speed camera to provide backlight illumination.

\subsection{Test fluids and experimental conditions}

Under actual SFR conditions, the dispersed and continuous phases are the mixed oxide (MOX) fuel and sodium, respectively., whose physical properties are given in Table $\mathbf{1}$ for reference. One of the major characteristics of the system is that sodium has a comparatively low viscosity. The physical properties in Table 1 will be used in Section 3.5 to estimate the reactor conditions. 
We employed two pairs of immiscible liquids as the test fluids, the combinations and physical properties of which are summarized in Table 2. The pairs were Fluorinert (FC72, 3M Co.) into water and water into silicone oil (KF-96L-0.65CS, Shin-Etsu Chemical), in both of which the heavier fluid was injected into the lighter fluid. The experiments were carried out at room temperature $\left(25^{\circ} \mathrm{C}\right)$. Note that the densities and viscosities of the continuous phases in Table $\mathbf{2}$ are of the same order as the actual conditions (Table 1).
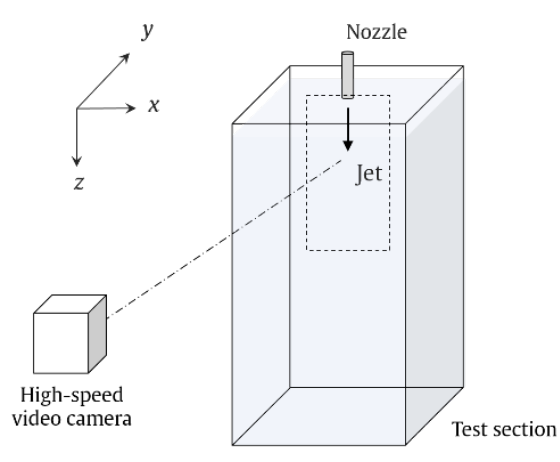

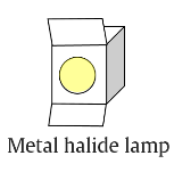

Fig. 2. Schematic diagram of experimental apparatus

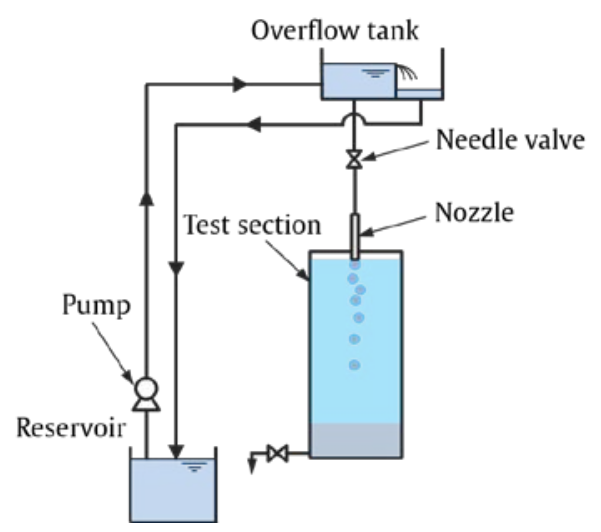

Table 1 Physical properties of SFR conditions (Chawla et al., 1981; Golden and Tokar, 1967).

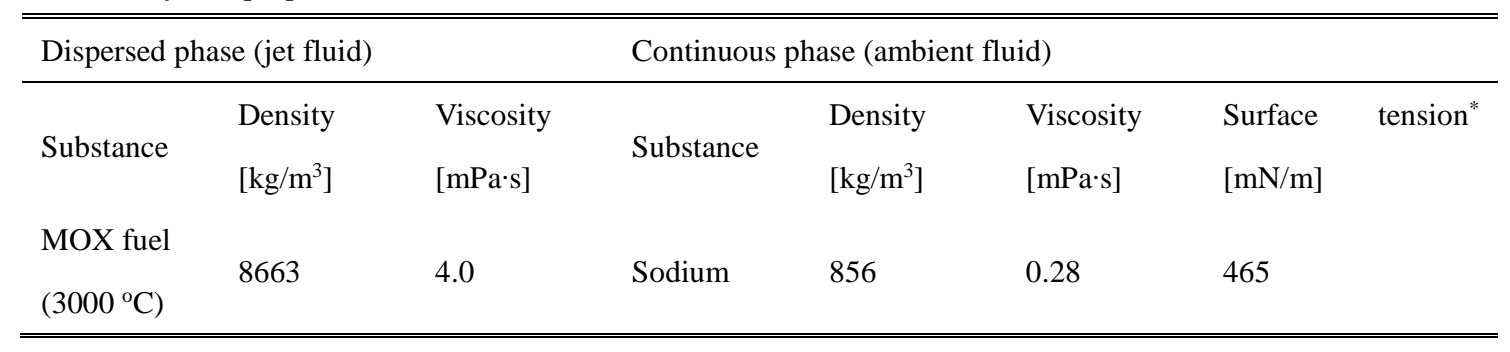

* The term "surface tension" indicates that the values are determined against the gas phase.

Table 2 Physical properties of test fluids at $25{ }^{\circ} \mathrm{C}$.

\begin{tabular}{|c|c|c|c|c|c|c|c|}
\hline \multicolumn{3}{|c|}{ Dispersed phase (jet fluid) } & \multicolumn{5}{|c|}{ Continuous phase (ambient fluid) } \\
\hline \multirow{2}{*}{ Substance } & Density & Viscosity & \multirow{2}{*}{ Substance } & Density & Viscosity & Interfacial & \multirow[t]{2}{*}{ tension } \\
\hline & {$\left[\mathrm{kg} / \mathrm{m}^{3}\right]$} & {$[\mathrm{mPa} \cdot \mathrm{s}]$} & & {$\left[\mathrm{kg} / \mathrm{m}^{3}\right]$} & {$[\mathrm{mPa} \cdot \mathrm{s}]$} & {$[\mathrm{mN} / \mathrm{m}]$} & \\
\hline FC-72 & 1680 & 0.67 & Water & 997 & 0.89 & 52 & \\
\hline Water & 997 & 0.89 & Silicone oil & 760 & 0.49 & 40 & \\
\hline
\end{tabular}


Manuscript for Nuclear Engineering and Design 


\section{Results and discussion}

\subsection{Typical breakup regimes and breakup-length curve}

Firstly, we conducted qualitative observations of the jet breakup regimes in the present experiments, typical snapshots of which are shown in Fig. 3. The test fluid pair was water (dispersed phase) and silicone oil (continuous phase); the nozzle diameter $D_{j 0}$ was $7 \mathrm{~mm}$. Thus, the variable parameter was the injection velocity $u_{j 0}$. From left to right, we can see that the droplet size decreased and the number of droplets increased with increase of jet velocity. Also, the scale of the waves on the interface became smaller with the velocity was increased.

Next, we measured the jet breakup length. The term breakup length refers to the length of the continuous liquid column from the nozzle (Lin and Reitz, 1998; McCarthy and Molloy, 1974). Jet breakup length is one of the indices that characterize the jet breakup behavior. The measured jet breakup length $L$ scaled on the nozzle diameter $D_{j 0}$ is plotted in Fig. 4 against the ambient Weber number $W e_{a}$ [Eq. (1)]. The conditions were the same as those mentioned in the previous paragraph. The jet breakup length was defined as the mean continuous jet length over $1.0 \mathrm{~s}$. The corresponding visual images are also included in the figure. The curve of jet breakup length in Fig. $\mathbf{4}$ shows certain characteristic behavior. With increase of $W e_{a}$, the breakup length increases at first to a local maximum, decreases to a local minimum, then increases again. For $W e_{a}>100$, it was difficult to identify the breakup length from the backlight visual images. Thus, results from index-matched laser-induced fluorescence (LIF) measurements are additionally plotted in Fig. 4 with the corresponding snapshots (Saito et al., 2015b). Note that the latter measurement results were processed based on vertical-plane images of the jet flow, and suggest that the Weber number dependence of the breakup length is no longer significant.

The variation in breakup length shown in Fig. $\mathbf{4}$ is similar to that reported for liquid-gas systems (Bürger et al., 1995; Ginsberg, 1985). It is also similar to results from numerical simulations of Wood's metal into water (Thakre et al., 2015). We found the quantitative tendency of the breakup-length curve for our liquid-liquid system to be similar to that for a liquid-gas system. 
(a)

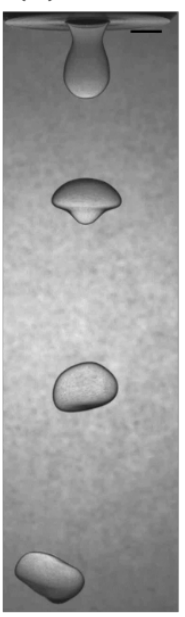

(b)

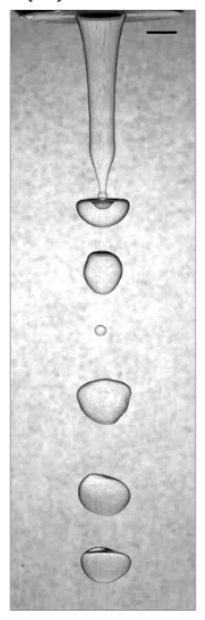

(c)

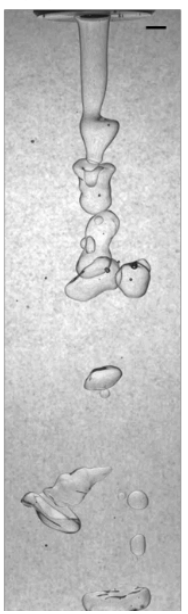

(d)

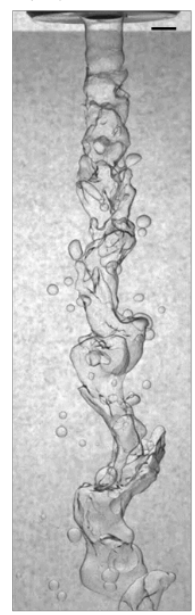

(e)

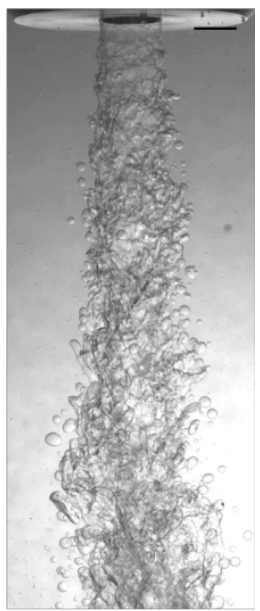

Fig. 3. Snapshots of typical breakup regimes observed in the experiments. The jet velocity increases from left to right: (a) $0.041 \mathrm{~m} / \mathrm{s}$, (b) $0.076 \mathrm{~m} / \mathrm{s}$, (c) $0.21 \mathrm{~m} / \mathrm{s}$, (d) $0.83 \mathrm{~m} / \mathrm{s}$, (e) $2.1 \mathrm{~m} / \mathrm{s}$. The scale bar in each image represents $5 \mathrm{~mm}$.

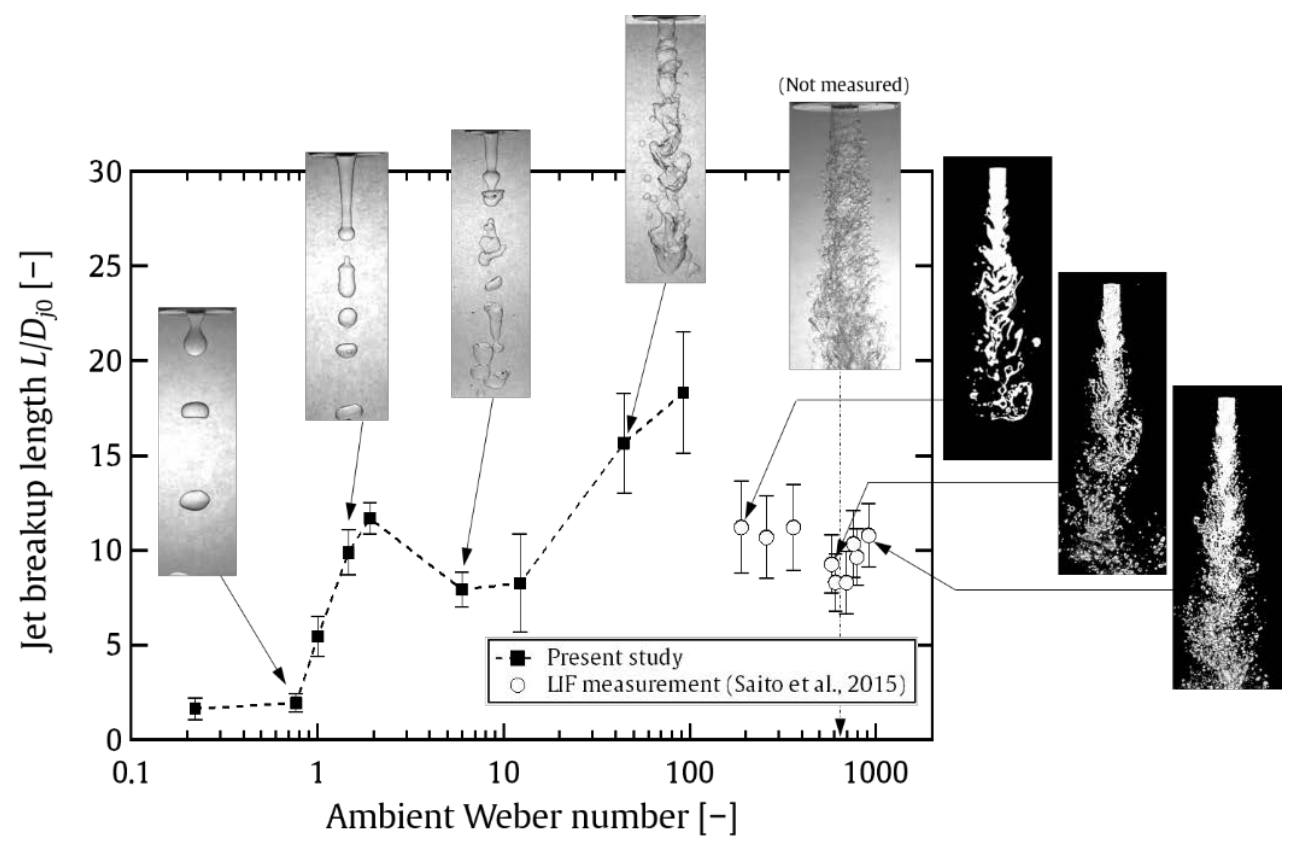

Fig. 4. Jet breakup length versus ambient Weber number. Open circles ( $\odot$ ) represent data obtained via planar LIF (laserinduced fluorescence) using the index-matching technique (Saito et al., 2015b). The three images on the right are of the vertical plane of the jet illuminated by a laser sheet. 


\subsection{Droplet formation process and droplet size distribution}

\subsubsection{Droplet analysis procedure}

Image processing was used to analyze the droplet size. Because the droplets were not necessarily circular in outline, an elliptical approximation was used instead to evaluate the droplet diameter.

Fig. 5 shows the original image to be processed [Fig. 5(a)] and the post-processed analyzed image [Fig. 5(b)]. The procedure of the present analysis can be summarized briefly as follows:

1. The five coordinate values were extracted from the visual image of droplets.

2. The elliptical approximation was applied to the five coordinate values.

3. An area-equivalent diameter was calculated from the ellipse equation.

The Cartesian coordinate system used for droplet analysis is shown schematically in Fig. 6. The shape of an ellipse with angle $\theta$ is given by

$$
\left[\frac{\left(x-x_{0}\right) \cos \theta+\left(y-y_{0}\right) \sin \theta}{a}\right]^{2}+\left[\frac{-\left(x-x_{0}\right) \sin \theta+\left(y-y_{0}\right) \cos \theta}{b}\right]^{2}=1
$$

where $a$ and $b$ are the major and minor half widths of the ellipse, respectively, and $\left(x_{0}, y_{0}\right)$ is the central point of the ellipse. Eq. (7) can be expanded as follows:

$$
x^{2}+A x y+B y^{2}+C x+D y+E=0,
$$

where $A, B, C, D$, and $E$ are constants. In the droplet analysis, the five coordinate values are substituted to Eq. (8), and then the area-equivalent diameter of the droplet $d_{e}$ was calculated by

$$
d_{e}=2 \sqrt{a b} .
$$

Hereinafter, we will evaluate the area-equivalent diameter $d_{e}$ as the droplet diameter $d$ using the aforementioned procedure.

(a)

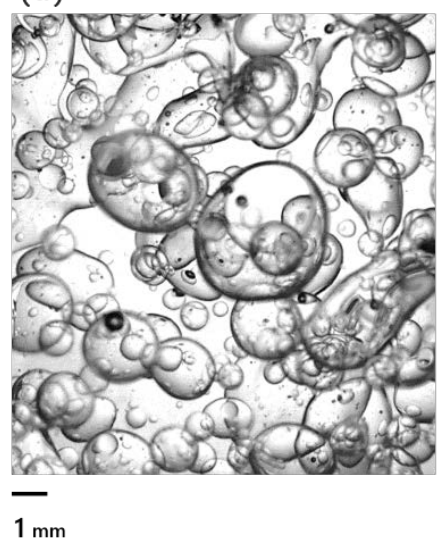

(b)

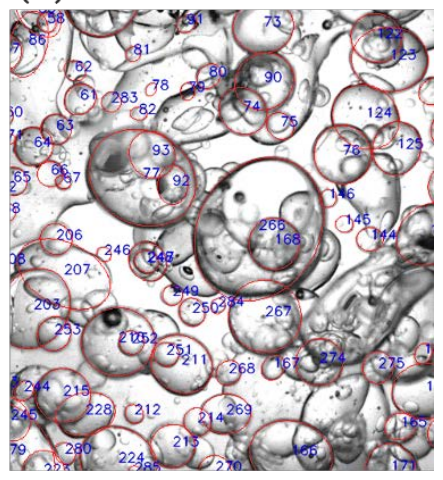

Fig. 5. Example of droplet size analysis: (a) pre-processed original image, (b) analyzed image. 


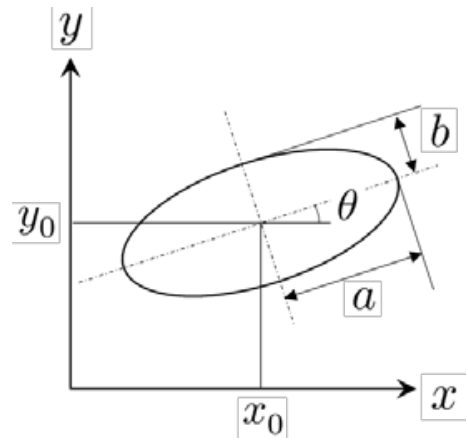

Fig. 6. Coordinate system for image processing of a droplet.

\subsubsection{Characteristics of breakup regimes}

We now classify the breakup regimes obtained from the experiments. In the present study, we extend the classical Ohnesorge classification (McKinley and Renardy, 2011; Ohnesorge, 1936) to liquidliquid systems based on the observation results. The five types of breakup regimes as shown in Fig. 3 are subjected to Ohnesorge's classification. A brief summary of the classified breakup regimes and their characteristics is given in Table 3. The Roman numerals for each regime correspond to those mentioned in Section 1, except for Regime II. Since different droplet-formation processes were observed experimentally, Regime II is divided into two sub-regimes: Regime IIa and Regime IIb. Details of the characteristics of each sub-regime are given later in this section.

Table 3 Summary of breakup regimes.

\begin{tabular}{ll}
\hline \hline Regime & Characteristics \\
\hline 0 & Dripping from nozzle (no jet formation) \\
I & Varicose breakup \\
IIa & Sinuous breakup without entrainment \\
IIb & Sinuous breakup with entrainment \\
III & Atomization \\
\hline \hline
\end{tabular}

Next, we investigate the droplet size and its distribution. The droplet size itself and its distribution are also considered to be characteristics of the jet breakup behavior in conjunction with the breakup length. The number of measured droplets $n$ was 100-500 depending on the conditions, although that of Regime 0 was only approximately 20. Since the injection velocity was very small in Regime 0 , fewer droplet images were available compared with the other regimes.

Fig. 7 shows typical snapshots of the whole jet flow (left panel), the vicinity of droplet formation (upper-right panel) and the evaluated droplet-size distribution (lower-right panel) in each breakup 
regime. The histograms show the probability density of the measured droplet diameter. The vertical axis, pdf (probability density function), is normalized by number of droplets $n$, thus the area is to be 1 when it is integrated over the entire range. The pdfs here are based not on droplet volume but on droplet number. The droplet formation process and characteristics of droplet size distribution in each regime are described below.

\subsubsection{Regime 0 (Dripping)}

The results for Regime 0 are shown in Fig. 7(a). A droplet formed very near the nozzle by expansion of the neck part; no obvious liquid column formed. The so-called pinch-off phenomenon was dominant during this breakup regime. The resulting droplet was marginally wider than the nozzle. This tendency is similar to that predicted by classical Rayleigh theory (Rayleigh, 1878) for a liquid column in a vacuum:

$$
d=\sqrt[3]{\frac{3 \pi}{1.4}} D_{j 0},
$$

Eq. (10) leads to $d \approx 1.89 D_{j 0}$, which appears to overestimate the present experimental results slightly. According to Kolev (2005), breakup in this regime is influenced by density ratio and gravity. The difference in density ratio between liquid-gas and liquid-liquid systems is considered to be partly responsible for such an overestimation.

\subsubsection{Regime I (Varicose breakup)}

The results for Regime I are shown in Fig. 7(b). Clearly, a continuous liquid column now formed from the nozzle, unlike in Regime 0. The liquid column was nearly axisymmetric (varicose), and droplets formed at its top. Two types of breakup pattern were observed in this regime: droplet pinchoff and the formation of satellite droplets just after the pinch-off. This explains the obvious doublepeaked histogram of droplet size. Since the satellite droplets were much smaller than the nozzle diameter, the two distributions can be easily identified. The larger one corresponds to pinch-off droplets whose sizes ranged around the nozzle diameter, which is a little different from classical theory (Rayleigh, 1878; Tomotika, 1935). As pointed out by Kitamura et al. (1982), the theoretical prediction may be valid only when the velocity difference across the interface is sufficiently small.

\subsubsection{Regime IIa (Sinuous breakup without entrainment)}

The results for Regime IIa are shown in Fig. 7(c). The liquid column transitioned to being asymmetric (sinuous) in this regime. However, droplets continued to form at the column tip, as in Regime I. The droplet size distribution seems to possess two peaks, but this tendency is no longer as clear as it is in Regime I. The observed process of droplet formation was again pinch-off and satellite 
formation.

One of the reasons why the liquid column became sinuous in this regime is considered to be that the settling velocity exceeded the jet velocity at the inlet. The settling velocity of a particle is given by

$$
u_{s}=\sqrt{\frac{4}{3 c_{f}}} \sqrt{\frac{\rho_{p}-\rho_{a}}{\rho_{a}} d_{p} g},
$$

where $c_{f}$ is the drag coefficient, $d_{p}$ is the particle diameter, $\rho_{p}$ is the particle density, and $\rho_{a}$ is the density of the ambient fluid. By replacing $\rho_{p}$ and $\rho_{a}$ with $\rho_{j}$ and $\rho_{c}$, respectively, and assuming that (i) the particle diameter $d_{p}$ for a pinch-off droplet is equal to the nozzle diameter $D_{j 0}$, and (ii) the drag coefficient acting on the particle is $c_{f} \approx 0.44$ (Newtonian regime), the settling velocity is evaluated as $u_{s} \approx 0.25 \mathrm{~m} / \mathrm{s}$ for the conditions in Fig. 3. The jet velocity in this regime [Fig. 3(c)] was $0.21 \mathrm{~m} / \mathrm{s}$, which is clearly comparable with the predicted settling velocity.

\subsubsection{Regime IIb (Sinuous breakup with entrainment)}

The results for Regime IIb are shown in Fig. 7(d). The sinuous shape of the liquid column was similar to that in Regime IIa. Regarding the droplet formation process, droplet entrainment at the side of the liquid column began in this regime, with pinch-off and satellite formation at the tip of the liquid column. As can be seen in the relevant histogram, the diameters of the entrainment and satellite droplets were less than the nozzle diameter. It was difficult to identify from the visual images whether such small droplets were due to satellite formation or entrainment. In this regime, droplets comparatively larger than the nozzle diameter could be observed, although they were few in number.

\subsubsection{Regime III (Atomization)}

The results for Regime III are shown in Fig. 7(e). The liquid column was now covered with a proliferation of entrainment droplets that were much smaller than the nozzle diameter. Note that in this regime, pinch-off and satellite formation may still have been occurring at the tip of the liquid column, but the overwhelming number of entrainment droplets prevented us from identifying such behavior. 

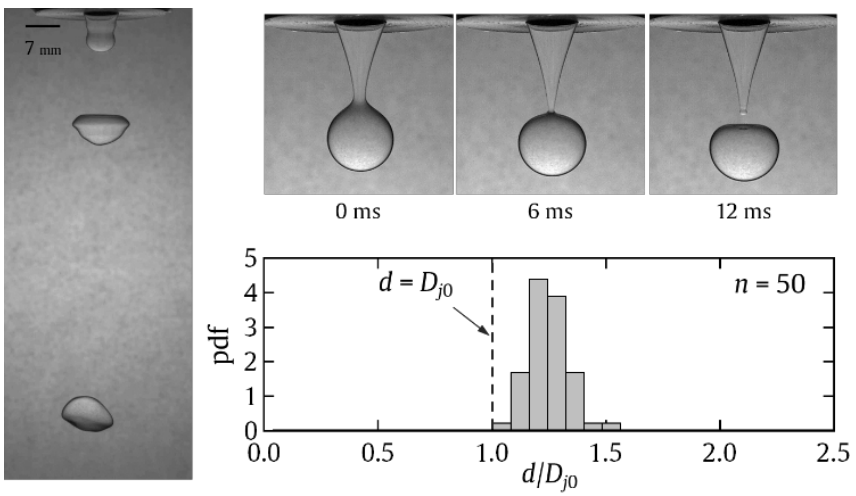

(a) Regime 0: Dripping from nozzle (no jet formation)
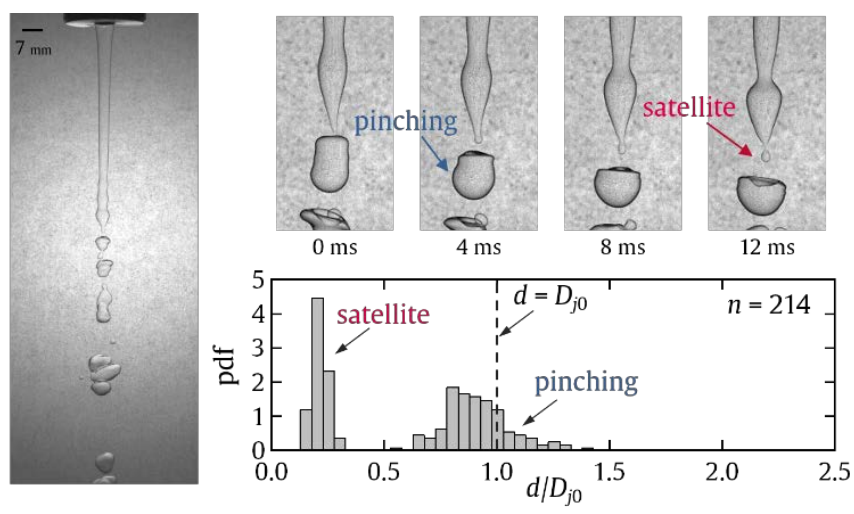

(b) Regime I: Varicose breakup
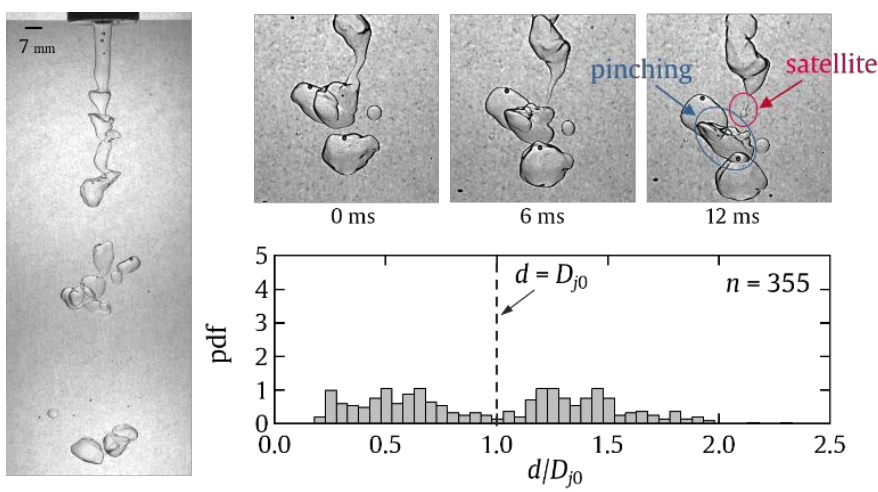

(c) Regime IIa: Sinuous breakup without entrainment

Fig. 7. Droplet formation process and evaluated droplet-diameter distribution in each breakup regime. 

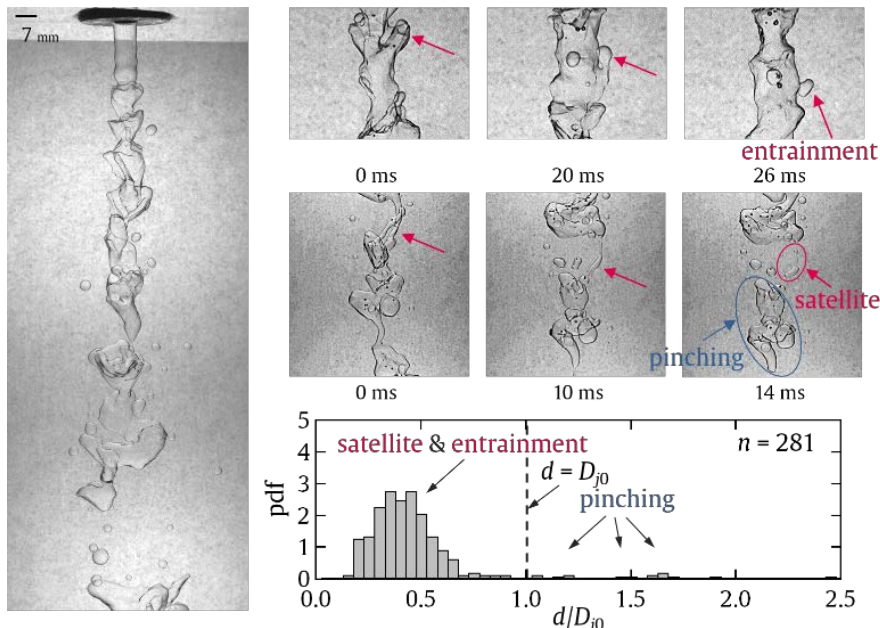

$20 \mathrm{~ms}$ $26 \mathrm{~ms}$

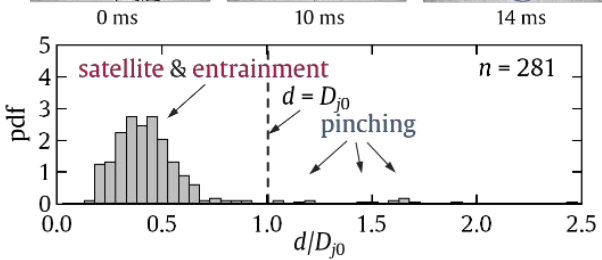

(d) Regime IIb: Sinuous breakup with entrainment
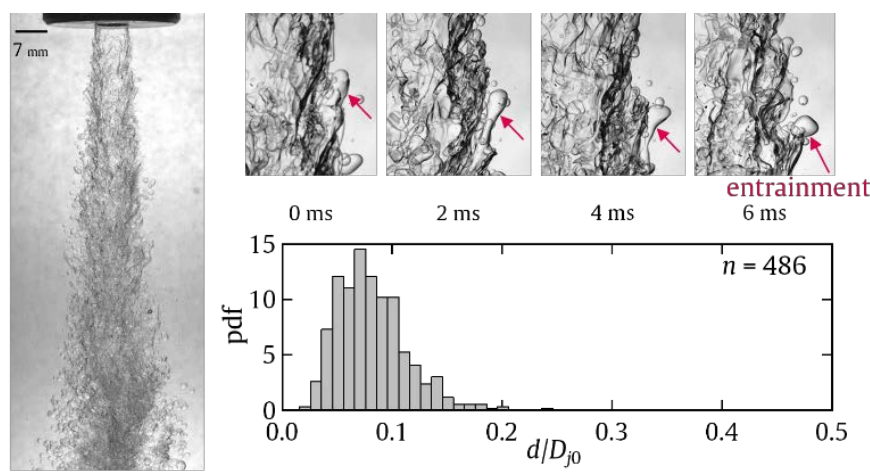

(e) Regime III: Atomization

Fig. 7. (continued)

The observed droplet-formation process can be finally classified to three types: pinch-off, satellite formation, and entrainment. It is known that the processes of breaking up into droplets can be divided into the so-called primary breakup (Gorokhovski and Herrmann, 2008; Pilch and Erdman, 1987) and secondary breakup (Guildenbecher et al., 2009; Jain et al., 2015) during liquid jet breakup (Lasheras et al., 1998). Primary breakup forms droplets directly from the liquid column, after which secondary breakup occurs depending on the flow conditions. Pinch-off and entrainment are elements of primary breakup; satellite drop formation is part of secondary breakup. Hereinafter, the droplets formed by primary breakup (pinch-off and satellite) and secondary breakup (satellite formation) will be considered separately for droplet size evaluation.

The distribution of droplet diameter and the typical droplet-formation process in each breakup regime are summarized in Fig. 8. We can see that the dominant process transitioned from pinch-off to entrainment with increase of jet velocity. Qualitatively, the characteristic droplet size decreases as we progress through the series of breakup transition regimes. 


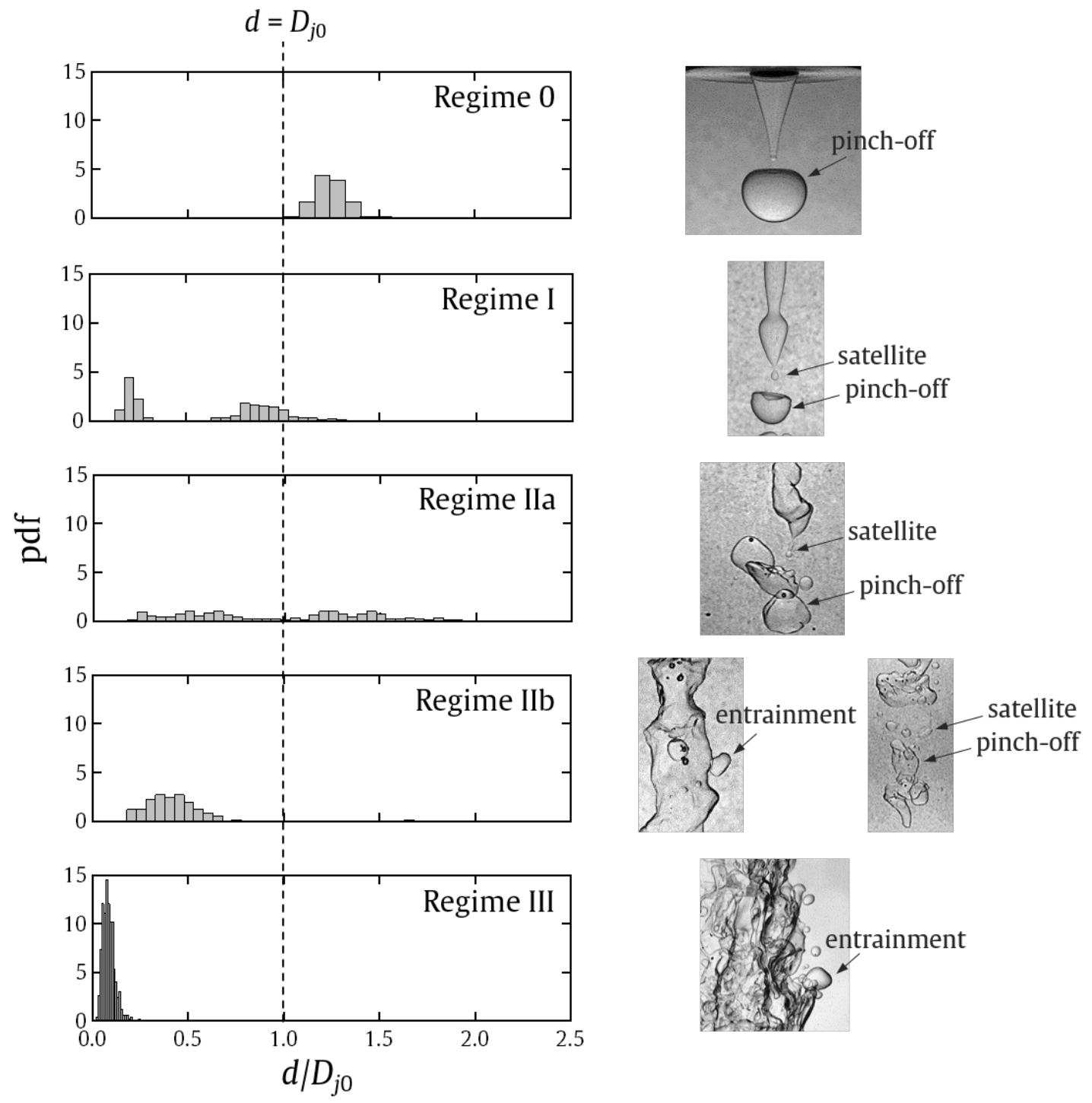

Fig. 8. Summary of transitions in droplet diameter distribution (left) with typical snapshots of the droplet formation process (right).

\subsection{Breakup regimes on dimensionless map}

The experimental results classified into the regimes defined in Table 3 are shown in Fig. 9 with available experimental data (Saito et al., 2015a; Takahashi and Kitamura, 1971). A schematic illustration describing the characteristics of each regime is also shown within the figure. For reference, the boundaries of the liquid-gas systems of Ohnesorge (1936) [Eqs. (5) and (6), obtained by Kolev (2005)] are drawn as the dashed lines. We can see that the correlations for liquid-gas systems cannot be applied to liquid-liquid systems on the diagram. The increase of ambient density is considered to 
be responsible for the difference between liquid-liquid and liquid-gas systems. In general, the density ratio (dispersed phase to continuous phase) $\gamma$ is of the order of 1 for liquid-liquid systems and 1,000 for liquid-gas systems. Modification or reformulation of the boundaries into those for liquid-liquid systems is required in order to predict the breakup regime in liquid-liquid systems.
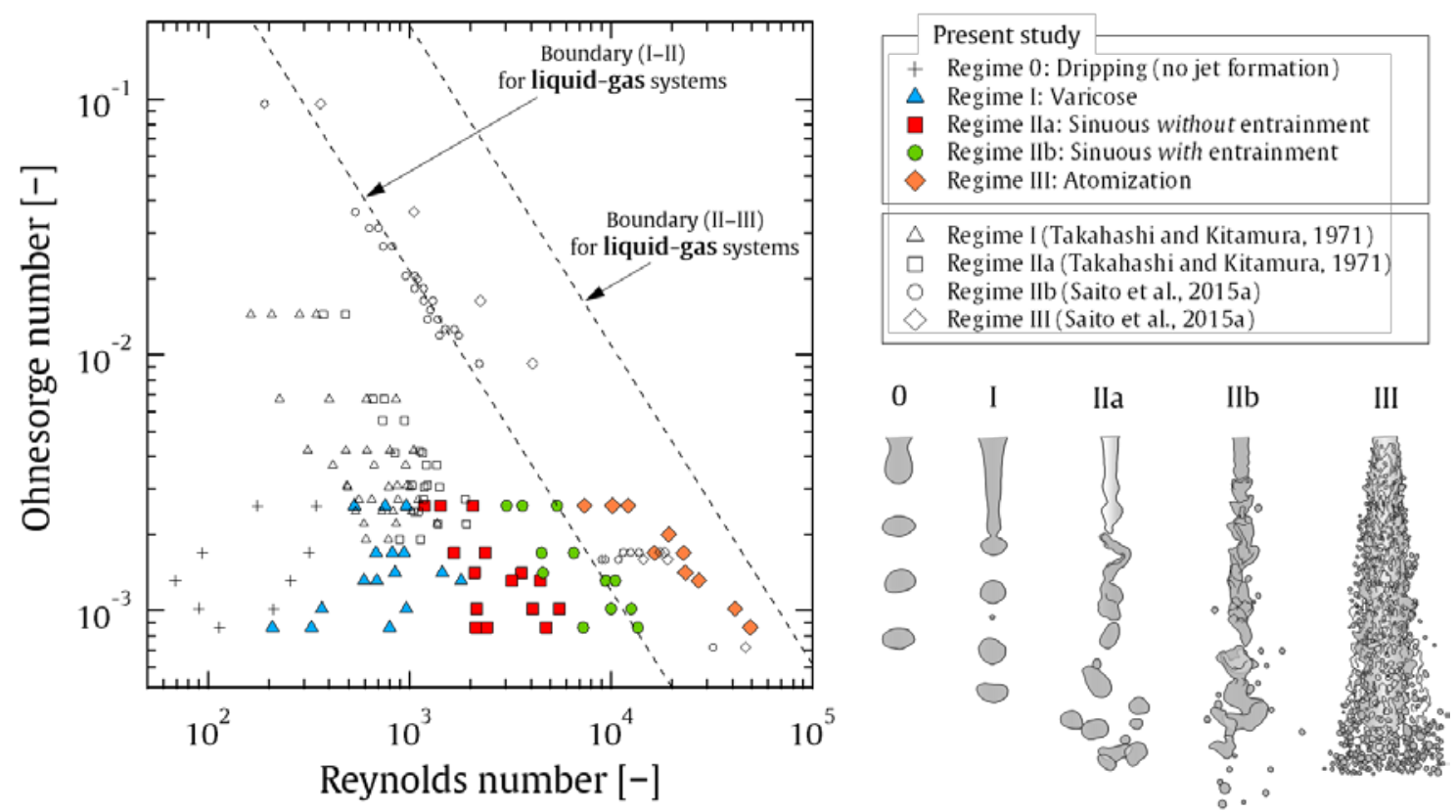

Fig. 9. Operating diagram of jet breakup regimes observed in the present experiments and in previous studies (Saito et al., 2015a; Takahashi and Kitamura, 1971). Dashed lines are the boundaries for liquid-gas systems obtained by Kolev (2005) based on Ohnesorge’s experimental data (Ohnesorge, 1936). The correlations for liquid-gas systems are not applicable to liquid-liquid systems.

\subsection{Evaluation of median diameter}

\subsubsection{Droplet size in each regime}

Next, we calculate the median diameter to evaluate the droplet size. Here we use the mass-median diameter (MMD) as the index of droplet size. The MMD has been employed by several authors to evaluate the fragment size during melt-coolant interactions (e.g., Matsuba et al., 2016b; Matsuo et al., 2008; Nishimura et al., 2010). Therefore, we can compare our results with the available data on the same basis. The discussion including available experiments will be given later.

The results plotted in Fig. 10 show the velocity dependence of MMD for $D_{j 0}=7 \mathrm{~mm}$ for water and silicone oil. It should be noted that we defined two MMDs for the same jet velocity condition when two peaks were observed in the droplet size distribution [e.g., Fig. 7(b) and (c)]. Such a double-peaked distribution was observed whenever satellite drops formed. Satellite droplets were smaller than pinch- 
off ones, but the numbers of each were comparable. This indicates that the total mass of the satellite droplets can be neglected, and that treating them separately would not yield a significant effect on the MMD. Singly distributed droplets and the larger ones in the double-distributions were mainly due to pinch-off or entrainment. Also, the vertical error bars in Fig. 10 indicate the 95\% confidence interval for MMD, which we use to express the width of the droplet size distributions even though the distributions were not necessarily Gaussian ones. Unless otherwise stated, the procedure mentioned in this paragraph will be adopted in the rest of this article.

From Fig. 10, we find that when the jet velocity is small (Regimes 0, I, and IIa), the droplets are either the same size as the nozzle diameter or a little larger. In contrast, at high velocity (Regime III), the droplet diameter seems to depend on the jet velocity.

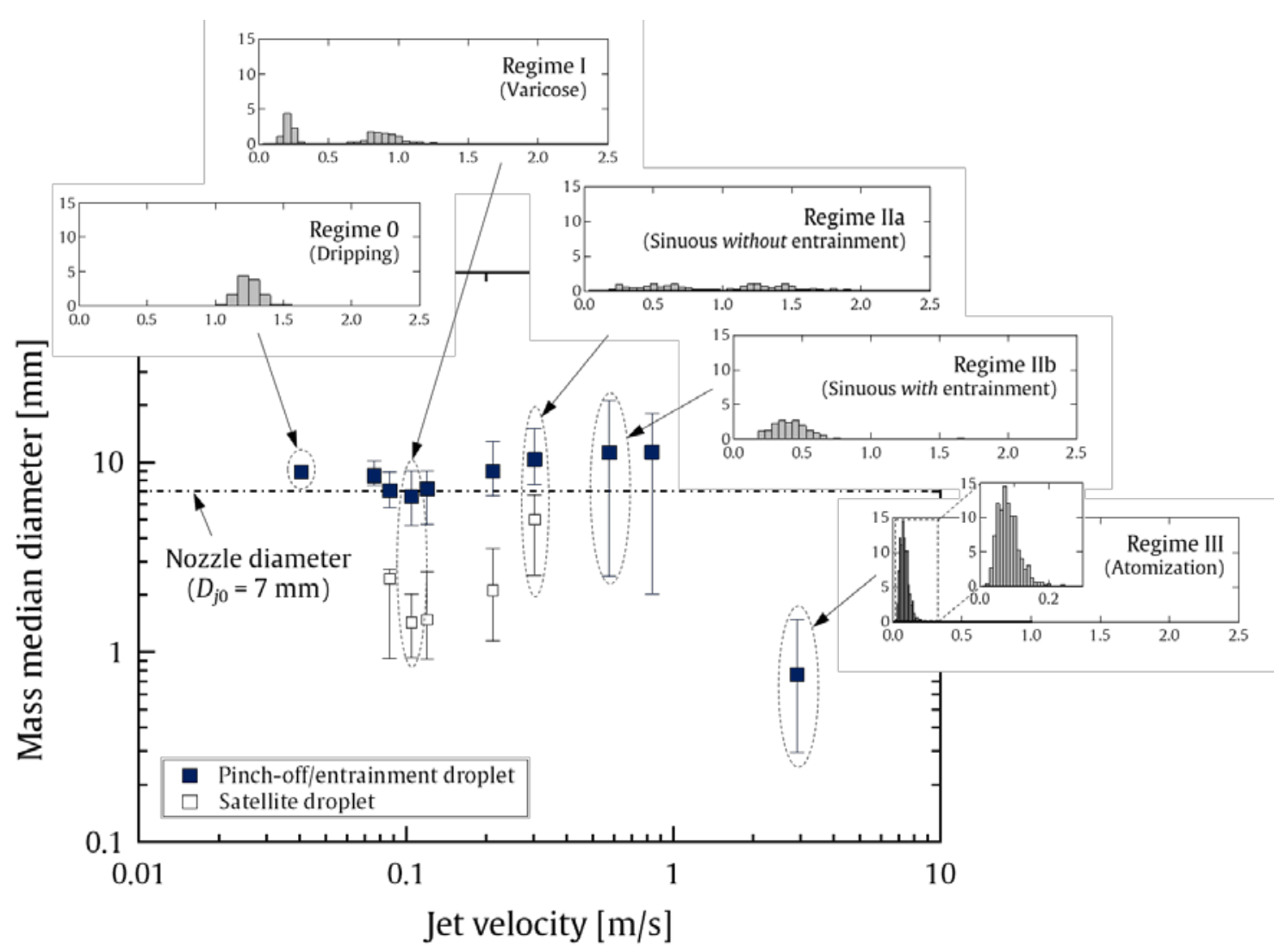

Fig. 10. Velocity dependence of droplet size, with histograms of droplet diameter distribution. The vertical and horizontal axes in the histograms denote the probability density and droplet diameter $\left(d / D_{j 0}\right)$, respectively. 


\subsubsection{Comparison with classical hydrodynamic instabilities}

According to previous work, the fragment size is affected by classical instabilities (Abe et al., 2004, 2005, 2006; Bang et al., 2003; Matsuo et al., 2008). The relationship between the evaluated droplet size and the critical wavelength of each instability is compared here.

The critical wavelengths of the classical Rayleigh-Taylor and Kelvin-Helmholtz instabilities in two-dimensions are given by (Chandrasekhar, 1961)

$$
\begin{gathered}
\lambda_{c r}=2 \pi\left[\frac{\sigma}{\left(\rho_{j}-\rho_{c}\right) g}\right]^{\frac{1}{2}}, \\
\lambda_{c r}=2 \pi \frac{\rho_{j}+\rho_{c}}{\rho_{j} \rho_{c}} \frac{\sigma}{u_{j 0}^{2}},
\end{gathered}
$$

respectively, where $\sigma$ is the interfacial tension and $g$ is the gravitational acceleration. The jet velocity is used as the scaling velocity under the assumption that the ambient fluid is stationary in Eq. (13). One can draw the critical wavelength curve for the data using the same physical quantities.

Fig. 11 shows the variation in MMD when jet velocity for various nozzle diameters, and the critical wavelength curves described by Eqs. (12)(13). The test fluid pair was again water/silicone oil. The wavelength of the Rayleigh-Taylor instability is constant $(26.4 \mathrm{~mm}$ for the present liquid-liquid system) with velocity, whereas that of the Kelvin-Helmholtz instability depends on the jet velocity. All the nozzle diameters used in the present study were smaller than the critical wavelength of the Rayleigh-Taylor instability. From Fig. 11, the size of the droplets formed at lower velocities are of the same order as the nozzle diameter and smaller than the wavelength of the Rayleigh-Taylor instability. The velocity dependence on droplet diameter seems to appear at higher velocity regardless of nozzle diameter. The slope of this variation is similar to that of the Kelvin-Helmholtz instability, although there is some discrepancy between droplet size and instability wavelength. In Fig. 11, the dominant mechanism of droplet formation transitioned from pinch-off to entrainment among $0.3-0.7 \mathrm{~m} / \mathrm{s}$. The observation through the present experiments showed that the size of the pinch-off droplets depended on the nozzle diameter. In contrast, the size of the entrainment droplets clearly depended on velocity regardless of nozzle diameter.

It is noticeable that that the velocity dependence seems to appear beyond the intersection point of the Rayleigh-Taylor and Kelvin-Helmholtz instabilities. This would imply that the intersection point is related to the transition between breakup regimes, namely whether or not entrainment dominates. 


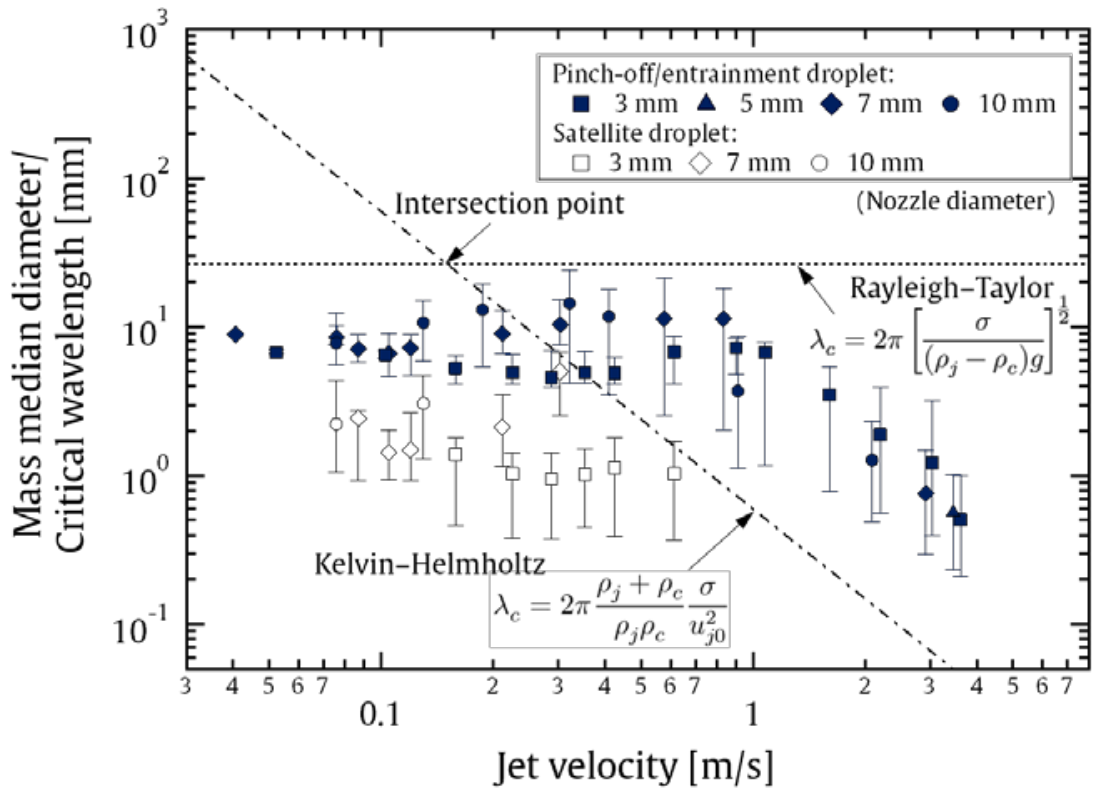

Fig. 11. Comparison of measured droplet diameter for variable nozzle diameters and two-dimensional hydrodynamic interfacial instability theories: Rayleigh-Taylor (dotted) and Kelvin-Helmholtz (broken) instabilities.

\subsubsection{Summary of droplet size and comparison with melt-coolant experiments}

Next, we plot all the present experimental results against the ambient Weber number [Eq. (1)] to summarize the data obtained in different systems and to quantitatively compare the available experimental data from melt-coolant systems.

Fig. 12 shows the droplet MMD obtained from the present experiments and the fragment MMD obtained from the previous works: U-alloy78/water system (Matsuo et al., 2008), copper/sodium system (Nishimura et al., 2010), and aluminum-oxide/sodium system (Matsuba et al., 2016b). The vertical axes in Fig. 12(a)(b) differ as to whether or not they are normalized by nozzle (inlet) diameter. The normalized MMD at lower Weber number is around $1\left(d=D_{j 0}\right)$ except for the satellite droplets [see Fig. 12(b)]. The normalized MMD obtained by Matsuba et al. (2016b) was evaluated as being much smaller than in the present liquid-liquid experiments. Two reasons for this can be considered. Firstly, the nozzle diameters used in their experiments were 40-63 mm, which is larger than those in other experiments (3-10 mm (present), 7-20 mm (Matsuo et al., 2008), 7.6-18 mm (Nishimura et al., 2010)). Based on such diameters, the normalized MMD of Matsuba et al. (2016b) results in much smaller values compared with the others. Secondly, Matsuba et al. used melt oxide as the jet material. As pointed out by Schins and Gunnerson (1986), the thermal stress characteristics of molten oxide lead to fracturing-type fragmentation. At higher Weber numbers, the non-normalized MMD of the present experiment and the previous data are well correlated [see Fig. 12(a)]. This seems to suggest 
that droplet formation at higher Weber numbers is dominated by the mechanisms that are independent of nozzle size; the Kelvin-Helmholtz instability correlates with droplet formation at higher Weber numbers. This fact is reasonable because the Kelvin-Helmholtz instability itself is independent of nozzle (inlet) diameter.

The threshold value at which the tendency of droplet or fragment size changes is found to be $W e_{a} \approx$ 20. This value is the same order of magnitude as the critical Weber numbers for droplets: 12 (Pilch and Erdman, 1987) or 18 (Matsuo et al., 2008).

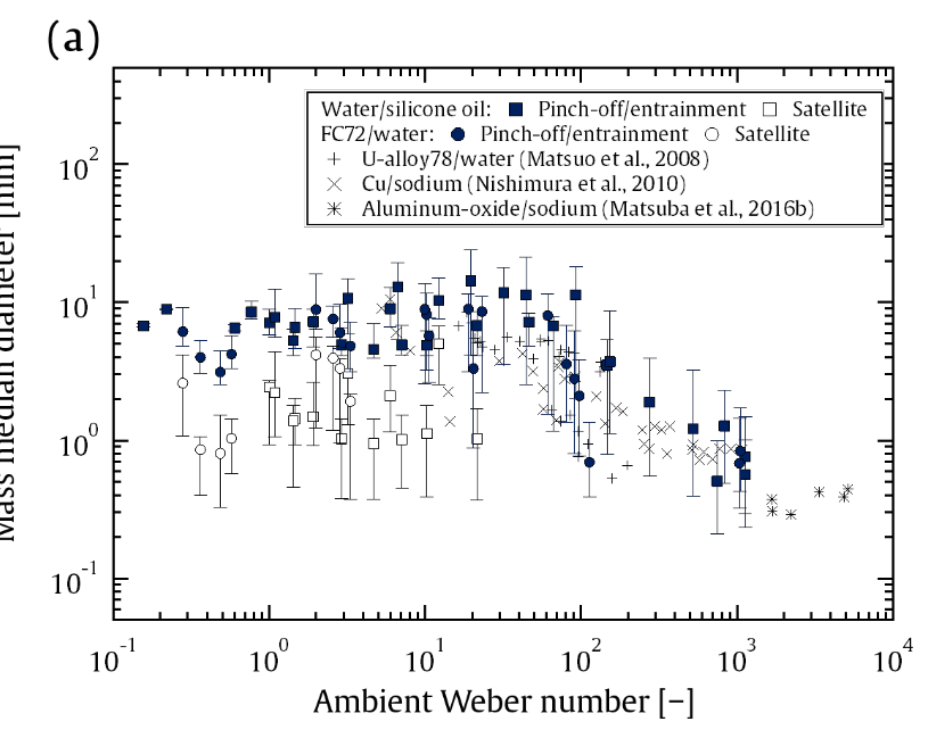

(b)

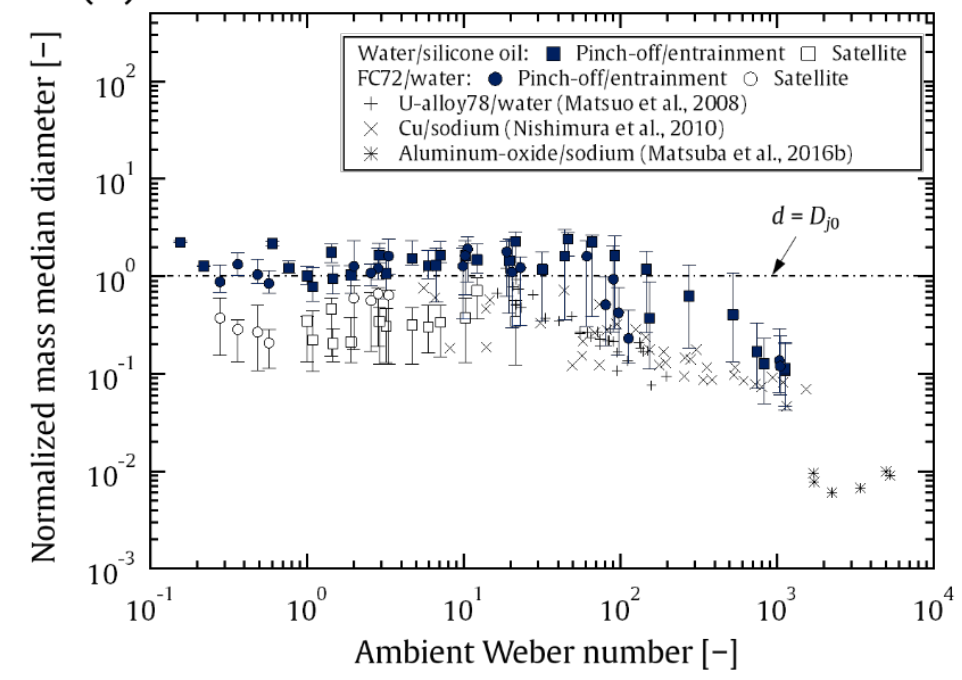

Fig. 12. Experimental results compared with available experimental data, including U-alloy 78/water (Matsuo et al., 2008), copper/sodium (Nishimura et al., 2010) and aluminum-oxide/sodium (Matsuba et al., 2016b): (a) normalized by nozzle diameter, (b) dimensional expression. 


\subsection{Breakup regime map for liquid-liquid systems}

\subsubsection{Formulation of breakup-regime boundaries}

As discussed in Section 3.4, the regime boundaries in liquid-gas systems are not suitable for liquidliquid systems on the dimensionless operating diagram. We consider the physical meanings of the boundaries for liquid-liquid systems and modify the boundaries.

In the framework of linear theory, the following dimensionless parameters are considered to describe the breakup of a viscous jet in a viscous fluid (Lin and Reitz, 1998):

$$
(\gamma, \eta, R e, W e, F r),
$$

where $\gamma$ is the density ratio and $\eta$ is the viscosity ratio. The Ohnesorge number can be written as $O h=$ $W e^{1 / 2} / R e$. By using the above dimensionless groups, we obtain the functional form on the Ohnesorge's operating diagram. We follow here the functional form expressed by Eq. (4).

As mentioned in Section 3.3, the transition from varicose to sinuous breakup (Regime IIa) may be explained from the viewpoint of the settling velocity of a formed pinch-off drop by Eq. (11). We assume that the transition from varicose breakup (Regime I) to sinuous breakup (Regime IIa) occurs at the point at which the jet velocity at the inlet corresponds to the settlement velocity:

$$
u_{j 0}=u_{s} \text { or } u_{j 0}=\sqrt{\frac{4}{3 c_{f}}} \sqrt{\frac{\rho_{j}-\rho_{c}}{\rho_{c}} D_{j 0} g} .
$$

By transforming Eq. (15) to the form of Eq. (4) using the dimensionless groups [Eq. (14)], one can obtain the following relation:

$$
O h=\left[\frac{4}{3 c_{f}}(\gamma-1) \cdot W e \cdot F r^{-1}\right]^{\frac{1}{2}} R e^{-1},
$$

where $\gamma=\rho_{j} / \rho_{c}$, We $=\rho_{j} u_{j 0}{ }^{2} D_{j 0} / \sigma$ and $F r=u_{j 0}{ }^{2} / g D_{j 0}$.

As mentioned in Subsection 3.4.2, the intersection point of the Rayleigh-Taylor and KelvinHelmholtz instabilities can be viewed as the transitional point. Beyond this point, the droplet size showed a clear dependence on the jet velocity, which suggests that entrainment now dominates the breakup behavior. Here, we assume the following relationship:

$$
2 \pi \sqrt{\frac{\sigma}{\left(\rho_{j}-\rho_{c}\right) g}}=2 \pi \frac{\rho_{j}+\rho_{c}}{\rho_{j} \rho_{c}} \frac{\sigma}{u_{j 0}^{2}} .
$$

With the dimensionless groups, Eq. (17) can be rewritten as

$$
O h=\left[(1+\gamma) \sqrt{1-\frac{1}{\gamma}} \cdot F^{-\frac{1}{2}}\right] R e^{-1} .
$$


We find that the value of the exponent part [or $b$ in Eq. (4)] is -1 in both Eqs. (16)(18) based on these simple assumptions. The coefficient [or $a$ in Eq. (4)] is, however, in a complicated form in both Eqs. (16)(18), so we determined the value instead by least-squares fitting the experimental data by using the breakup-regime data as shown in Fig. 13. Finally, the following correlations describing the boundaries of each breakup regime in liquid-liquid systems can be obtained from the present study and previous work (Saito et al., 2015a; Takahashi and Kitamura, 1971):

$$
\begin{aligned}
& O h=2.8 R e^{-1} \text { (between Regimes I and IIa), } \\
& O h=22 R e^{-1} \text { (between Regimes IIb and III). }
\end{aligned}
$$

The ambient viscosities considered in Eqs. (19)(20) were 0.36-0.89 $\mathrm{mPa} \cdot \mathrm{s}$; the related dimensionless parameters [appeared in Eqs. (16)(18)] were $\gamma=1.3-1.8$, We $=8.2 \times 10^{-3}-1.3 \times 10^{3}$, and $\mathrm{Fr}=$ $2.9 \times 10^{-3}-1.1 \times 10^{2}$.

(a)

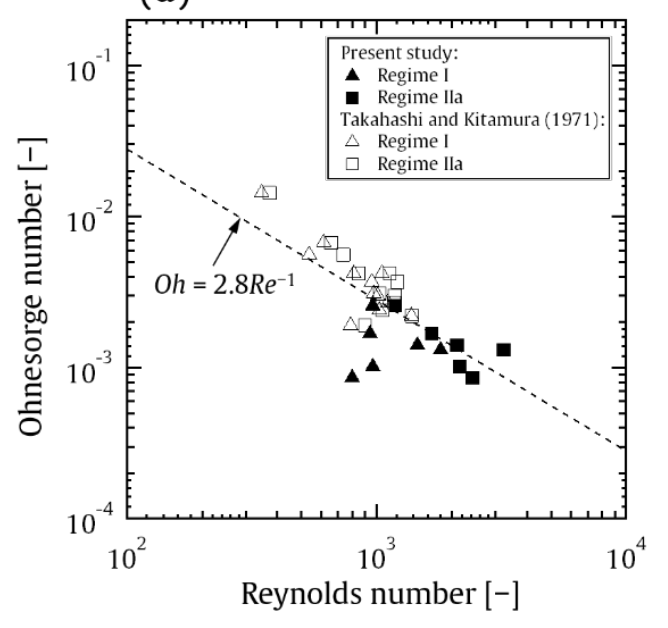

(b)

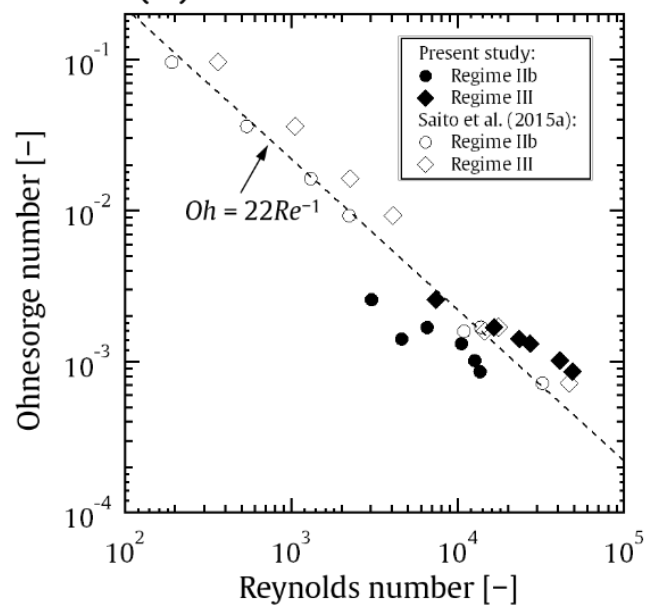

Fig. 13 Fitting to determine the coefficient between: (a) Regime I and Regime IIa, (b) Regime IIb and III.

\subsubsection{Summary of experimental data and extrapolation to SFR accident conditions}

Fig. 14 summarizes again the experimental results with the obtained boundaries for liquid-liquid breakup regimes [Eqs. (19)(20)]. On the diagram, the boundaries for liquid-liquid systems result in being located in the left-hand side compared with those for liquid-gas systems. As discussed in Section 3.3, the difference of density ratio in each system is considered to be responsible for such a shift in the diagram.

The boundaries of the jet breakup regimes were extrapolated to the region in which no experimental data is available. The FARO/TERMOS experiments $\left(\mathrm{UO}_{2} /\right.$ sodium system) carried out by Magallon et al. (1992) are also plotted in Fig. 14 with the symbol ' $X$ ', where the release channel diameter and the velocity upon impact with the sodium [see Table 1 of Magallon et al. (1992)] were taken as the 
characteristic length and velocity, respectively. We find that Magallon's experimental data are in the atomization regime. One of the characteristics of jet atomization is that the droplets are much smaller than the jet diameter (Lin and Reitz, 1998). From a hydrodynamic viewpoint, this might explain the fact reported by Magallon et al. (1992) that the debris was observed to be fine fragments whose size was of the order of $10^{1}-10^{3} \mu \mathrm{m}$.

The expected SFR conditions are also shown in Fig. 14 as the closed (grey) region with dashed line. The reactor conditions were estimated using the physical properties of the dispersed phase in Table 1 and the following conditions:

- jet diameter $D_{j 0}=10-500 \mathrm{~mm}$,

- jet velocity $u_{j 0}=0.5-50 \mathrm{~m} / \mathrm{s}$.

By using the above assumptions, the $\mathrm{UO}_{2}$ /sodium data of Magallon et al. (1992) can be included in the reactor conditions. We can see that most of the expected reactor conditions are located in Regime III. It is only the case of low jet velocity and small diameter $\left(u_{j 0}=0.5 \mathrm{~m} / \mathrm{s}\right.$ and $\left.D_{j 0}=10 \mathrm{~mm}\right)$ that is in Regime II. The reactor conditions do not extend to Regimes 0 or I under the aforementioned assumptions. Of course, thermal interactions could be involved in promoting jet breakup in actual situations, such as the local vaporization of sodium (Matsuba et al., 2016b) or surface freezing (Fauske et al., 2002). However, the hydrodynamic interactions considered in this article imply that the jet breakup regimes under SFR conditions appear to be in the atomization regime. Thus, the fragments would be much smaller than the jet diameter in an actual reactor.
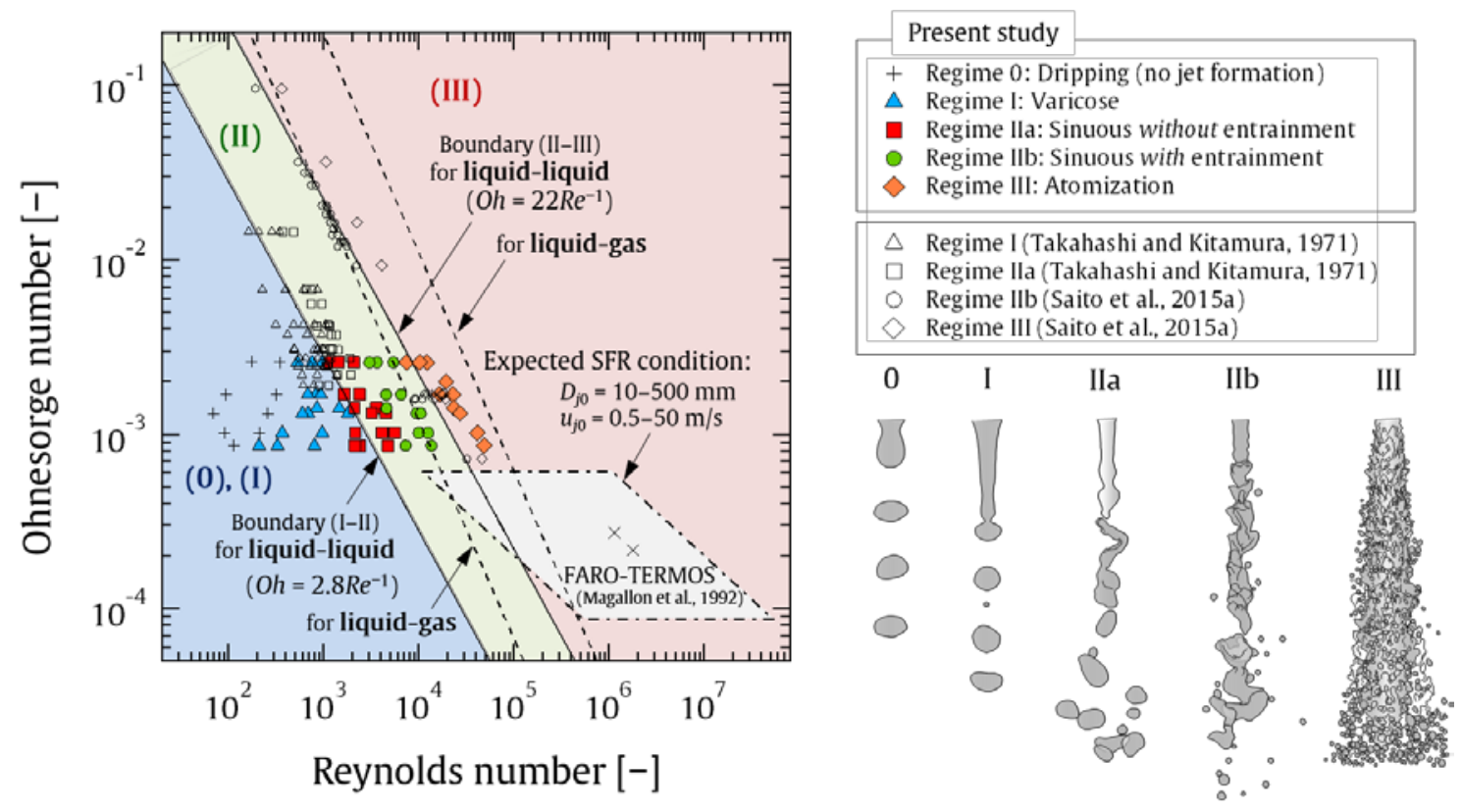

Fig. 14. Flow transition criteria of jets in liquid-liquid systems with experimental data and expected accident conditions. 


\section{Conclusions}

The dynamics of jet breakup and droplet formation in immiscible liquid-liquid systems were studied experimentally in order to better understand the fundamental interactions between a melt jet and the surrounding coolant during a CDA at an SFR. We performed experiments using two-types of test-fluid pairs under isothermal conditions.

The jet breakup behavior was observed by changing the jet velocity. The variation of measured breakup length with ambient Weber number obtained in the present liquid-liquid system was similar to that in a liquid-gas system. The breakup regimes were classified based on Ohnesorge's idea.

However, it was found that the empirical correlations representing the boundaries of the breakup regimes in liquid-gas systems could not be applied to liquid-liquid systems.

The droplet size distribution in each breakup regime was analyzed using image processing. Observations showed that pinch-off, entrainment, and satellite formation appeared as the droplet formation process. The characteristics of the droplet diameter distribution changed demonstrably with the breakup-regime transitions. The velocity-dependence of droplet size was confirmed when entrainment was dominant. Comparison with hydrodynamic instabilities suggested that the velocitydependence was correlated with the Kelvin-Helmholtz instability. The variation of droplet size with ambient Weber number was compared between the present study and available melt-jet experiments. The droplet diameter normalized by the inlet diameter was well correlated with Weber number at lower Weber numbers; at higher Weber numbers, the droplet size in dimensional (non-normalized) form was well correlated with Weber number.

Based on the observation and analysis results, the breakup regimes were organized on a dimensionless operating diagram. By using simple assumptions, the correlations representing the criteria for the regime boundaries of liquid-liquid systems were derived as follows:

$$
\begin{aligned}
& O h=2.8 R e^{-1} \text { (between Regimes I and IIa), } \\
& O h=22 R e^{-1} \text { (between Regimes IIb and III). }
\end{aligned}
$$

Finally, extrapolation of the experimental data to the expected conditions of an SFR was considered. The extrapolation results implied that most of the hydrodynamic conditions during an accident would be covered by Regime III, the atomization regime. It should be noted that the present results were performed under isothermal liquid-liquid systems, thus they did not simulate a high-temperature conditions with phase changes from the views of prototypicality. It is necessary to separately evaluate the thermal interactions; such studies have also been carried out by many researchers (e.g., surface solidification (Iwasawa et al., 2015b, 2015c) and coolant subcooling (Manickam et al., 2016)). As far as the SFR conditions are considered, thermal interactions would promote jet fragmentation (Suzuki et al., 2014a). A careful consideration on the thermal interactions in the reactor conditions should be taken into account to assess the reactor conditions. However, the authors believe that the results 
obtained in this article, based on the phenomenological discussion supported by the detailed experiments, provide fundamental knowledge with which to assess melt-jet breakup and fragmentation under the conditions that would pertain to an accident conditions.

\section{Acknowledgements}

This work was supported by Mitsubishi Heavy Industries, Ltd. The authors are grateful to H. Sakaba and H. Sato for their invaluable support. S.S. is grateful to A. Kaneko and T. Kanagawa for helpful discussions. The support of JSPS KAKENHI Grant Number 16J02077 is also acknowledged.

\section{References}

Abe, Y., Kizu, T., Arai, T., Nariai, H., Chitose, K., Koyama, K., 2004. Study on thermal-hydraulic behavior during molten material and coolant interaction. Nucl. Eng. Des. 230, 277-291. http://dx.doi.org/10.1016/j.nucengdes.2003.11.032

Abe, Y., Kizu, T., Nariai, H., Chitose, K., Koyama, K., 2005. Study on the quench behaviour of molten fuel material jetted into coolant. Trans. Jpn. Soc. Mech. Eng. Ser. B 71, 947-953. http://dx.doi.org/10.1299/kikaib.71.947

Abe, Y., Matsuo, E., Arai, T., Nariai, H., Chitose, K., Koyama, K., Itoh, K., 2006. Fragmentation behavior during molten material and coolant interactions. Nucl. Eng. Des. 236, 1668-1681. http://dx.doi.org/10.1016/j.nucengdes.2006.04.008

Abe, Y., Matsuo, E., Nariai, H., Chitose, K., Koyama, K., Itoh, K., 2007. Study on breakup behavior on molten material jet surface in coolant, in: 15th International Conference on Nuclear Engineering. Nagoya, Japan, ICONE1510182.

Bang, K.H., Kim, J.M., Kim, D.H., 2003. Experimental study of melt jet breakup in water. J. Nucl. Sci. Technol. 40, 807-813. http://dx.doi.org/10.1080/18811248.2003.9715422

Bang, K.H., Kim, H.T., 2014. Hydrodynamic aspect of jet breakup in liquid-liquid system and application to fuelcoolant interactions in a fully-flooded reactor cavity, in: 9th Korea-Japan Symposium on Nuclear Thermal Hydraulics and Safety. Buyeo, Korea, N9P0061.

Bürger, M., Cho, S.H., Berg, E. v., Schatz, A., 1995. Breakup of melt jets as pre-condition for premixing: modeling and experimental verification. Nucl. Eng. Des. 155, 215-251. http://dx.doi.org/10.1016/0029-5493(94)00875-Y

Chandrasekhar, S., 1961. Hydrodynamic and hydromagnetic stability. Oxford University Press, New York.

Chawla, T.C., Graff, D.L., Borg, R.C., Bordner, G.L., Weber, D.P., Miller, D., 1981. Thermophysical properties of mixed oxide fuel and stainless steel type 316 for use in transition phase analysis. Nucl. Eng. Des. 67, 57-74. http://dx.doi.org/10.1016/0029-5493(81)90155-2

Cho, S.H., Berg, E., Bürger, M., Schatz, A., 1991. Experimental investigations with respect to the modelling of fragmentation in parallel shear flows of liquids, in: Sprays and Aerosols Conference. Guildford, U.K., pp. 165- 


\section{Manuscript for Nuclear Engineering and Design}

169.

Das, T.K., 1997. Prediction of jet breakup length in liquid-liquid systems using the Rayleigh-Tomotika analysis. At. Sprays 7, 549-559. http://dx.doi.org/10.1615/AtomizSpr.v7.i5.70

Dinh, T.N., Bui, V.A., Nourgaliev, R.R., Green, J.A., Sehgal, B.R., 1999. Experimental and analytical studies of melt jet-coolant interactions: a synthesis. Nucl. Eng. Des. 189, 299-327. http://dx.doi.org/10.1016/S00295493(98)00275-1

Eggers, J., Villermaux, E., 2008. Physics of liquid jets. Reports Prog. Phys. 71, 36601. http://dx.doi.org/10.1088/0034$\underline{4885 / 71 / 3 / 036601}$

Epstein, M., Fauske, H.K., 2001. Applications of the turbulent entrainment assumption to immiscible gas-liquid and liquid-liquid systems. Chem. Eng. Res. Des. 79, 453-462. http://dx.doi.org/10.1205/026387601750282382

Fauske, H.K., Koyama, K., Kubo, S., 2002. Assessment of the FBR core disruptive accident (CDA): the role and application of general behavior principles (GBPs). J. Nucl. Sci. Technol. 39, 615-627. http://dx.doi.org/10.1080/18811248.2002.9715242

Ginsberg, T., 1985. Liquid jet breakup characterization with application to melt-water mixing, in: ANS Proceedings of National Heat Transfer Conference. Denver, USA

Golden, G.H., Tokar, J. V., 1967. Thermophysical properties of sodium. ANL-7323. Argonne National Laboratory.

Gorokhovski, M., Herrmann, M., 2008. Modeling primary atomization. Annu. Rev. Fluid Mech. 40, 343-366. http://dx.doi.org/10.1146/annurev.fluid.40.111406.102200

Grant, R.P., Middleman, S., 1966. Newtonian jet stability. AIChE J. 12, 669-678. doi:10.1002/aic.690120411

Guildenbecher, D.R., López-Rivera, C., Sojka, P.E., 2009. Secondary atomization. Exp. Fluids 46, 371-402. http://dx.doi.org/10.1007/s00348-008-0593-2

Huhtiniemi, I., Magallon, D., 2001. Insight into steam explosions with corium melts in KROTOS. Nucl. Eng. Des. 204, 391-400. http://dx.doi.org/10.1016/S0029-5493(00)00319-8

Iwasawa, Y., Abe, Y., Kaneko, A., Kanagawa, T., Saito, S., Matsuo, E., Ebihara, K., Sakaba, H., Koyama, K., Nariai, H., 2015a. Numerical study on influence of Ohnesorge number and Reynolds number on the jet breakup behavior using the lattice Boltzmann method, in: 23rd International Conference on Nuclear Engineering. Japan Sciety of Mechanical Engineers, Chiba, Japan, ICONE23-1950.

Iwasawa, Y., Abe, Y., Matsuo, E., Koyama, K., 2015b. Jet breakup behavior with surface solidification. Trans. JSME 81, 1-15. http://dx.doi.org/10.1299/transjsme.14-00460

Iwasawa, Y., Abe, Y., Matsuo, E., Koyama, K., 2015c. Effects of surface solidification on fragmentation behavior of molten material jet. Trans. JSME 81, 1-20. http://dx.doi.org/10.1299/transjsme.15-00147

Jain, M., Prakash, R.S., Tomar, G., Ravikrishna, R. V., 2015. Secondary breakup of a drop at moderate Weber numbers. Proc. R. Soc. A Math. Phys. Eng. Sci. 471, 20140930-20140930. http://dx.doi.org/10.1098/rspa.2014.0930

Kaiser, A., Huber, F., Wilhelm, D., 1998. Experiments on the behaviour of a hot melt injected into sodium. Exp. Therm. Fluid Sci. 18, 48-69. http://dx.doi.org/10.1016/S0894-1777(98)10008-0

Kaiser, A., Schütz, W., Will, H., 2001. PREMIX experiments PM12-PM18 to investigate the mixing of a hot melt with 


\section{Manuscript for Nuclear Engineering and Design}

water. FZKA-6380. Forschungszentrum Karlsruhe.

Karbojian, A., Ma, W.M., Kudinov, P., Dinh, T.N., 2009. A scoping study of debris bed formation in the DEFOR test facility. Nucl. Eng. Des. 239, 1653-1659. http://dx.doi.org/10.1016/j.nucengdes.2009.03.002

Kitamura, Y., Mishima, H., Takahashi, T., 1982. Stability of jets in liquid-liquid systems. Can. J. Chem. Eng. 60, 723731. http://dx.doi.org/10.1002/cjce.5450600602

Kolev, N.I., 2005. Multiphase flow dynamics 2, 3rd ed. Springer-Verlag, Berlin/Heidelberg. http://dx.doi.org/10.1007/b138146

Kolev, N.I., 2015. Private communication.

Kondo, S., Konishi, K., Isozaki, M., Imahori, S., Furutani, A., Brear, D.J., 1995. Experimental study on simulated molten jet-coolant interactions. Nucl. Eng. Des. 155, 73-84. http://dx.doi.org/10.1016/0029-5493(94)00870-5

Kudinov, P., Karbojian, A., Tran, C.-T., Villanueva, W., 2013. Agglomeration and size distribution of debris in DEFOR-A experiments with $\mathrm{Bi}_{2} \mathrm{O}_{3}-\mathrm{WO}_{3}$ corium simulant melt. Nucl. Eng. Des. 263, $284-295$. http://dx.doi.org/10.1016/j.nucengdes.2013.06.011

Kuroda, T., Abe, Y., Kaneko, A., Iwasawa, Y., Nariai, H., Sakaba, H., Koyama, K., Matsuo, E., Ebihara, K., 2012. Combined measurement of PIV and LIF for fragmentation behavior on jet breakup, in: 8th Korea-Japan Symposium on Nuclear Thermal Hydraulics and Safety. Beppu, Japan, N8P1042.

Lasheras, J.C., Villermaux, E., Hopfinger, E.J., 1998. Break-up and atomization of a round water jet by a high-speed annular air jet. J. Fluid Mech. 357, S0022112097008070. http://dx.doi.org/10.1017/S0022112097008070

Lin, S.P., Reitz, R.D., 1998. Drop and spray formation from a liquid jet. Annu. Rev. Fluid Mech. 30, 85-105. http://dx.doi.org/10.1146/annurev.fluid.30.1.85

Longmire, E.K., Norman, T.L., Gefroh, D.L., 2001. Dynamics of pinch-off in liquid/liquid jets with surface tension. Int. J. Multiphase Flow 27, 1735-1752. http://dx.doi.org/10.1016/S0301-9322(01)00030-1

Magallon, D., Hohmann, H., Schins, H., 1992. Pouring of 100-kg-scale molten $\mathrm{UO}_{2}$ into sodium. Nucl. Technol. 98, 79-90.

Magallon, D., Huhtiniemi, I., 2001. Corium melt quenching tests at low pressure and subcooled water in FARO. Nucl. Eng. Des. 204, 369-376. http://dx.doi.org/10.1016/S0029-5493(00)00318-6

Magallon, D., 2006. Characteristics of corium debris bed generated in large-scale fuel-coolant interaction experiments. Nucl. Eng. Des. 236, 1998-2009. http://dx.doi.org/10.1016/j.nucengdes.2006.03.038

Manickam, L., Thakre, S., Ma, W., Bechta, S., 2014. Simultaneous visual acquisition of melt jet breakup in water by high speed videography and radiography, in: 10th International Topical Meeting on Nuclear Thermal-Hydraulics, Operation and Safety. Okinawa, Japan, NUTHOS10-1313.

Manickam, L., Kudinov, P., Ma, W., Bechta, S., Grishchenko, D., 2016. On the influence of water subcooling and melt jet parameters on debris formation. Nucl. Eng. Des. 309, 265-276. http://dx.doi.org/10.1016/j.nucengdes.2016.09.017

Mathai, A.M., Sharma, A.K., Anandan, J., Malarvizhi, B., Das, S.K., Nashine, B.K., Chellapandi, P., 2015. Investigation of fragmentation phenomena and debris bed formation during core meltdown accident in SFR 


\section{Manuscript for Nuclear Engineering and Design}

using simulated experiments. Nucl. Eng. Des. 292, 87-97. http://dx.doi.org/10.1016/j.nucengdes.2015.06.002

Matsuba, K., Kamiyama, K., Toyooka, J., Tobita, Y., Zuev, V.A., Kolodeshnikov, A.A., Vasilyev, Y.S., 2015. Experimental discussion on fragmentation mechanism of molten oxide discharged into a sodium pool, in: 23rd International Conference on Nuclear Engineering. Chiba, Japan, ICONE23-1603.

Matsuba, K., Isozaki, M., Kamiyama, K., Tobita, Y., 2016a. Distance for fragmentation of a simulated molten-core material discharged into a sodium pool. J. Nucl. Sci. Technol. 53, 707-712. http://dx.doi.org/10.1080/00223131.2015.1113897

Matsuba, K., Kamiyama, K., Toyooka, J., Tobita, Y., Zuev, V.A., Kolodeshnikov, A.A., Vassiliev, Y.S., $2016 b$. Experimental discussion on fragmentation mechanism of molten oxide discharged into a sodium pool. Mech. Eng. J. 3, 15-595-15-00595. http://dx.doi.org/10.1299/mej.15-00595

Matsuo, E., Abe, Y., Chitose, K., Koyama, K., Itoh, K., 2008. Study on jet breakup behavior at core disruptive accident for fast breeder reactor. Nucl. Eng. Des. 238, 1996-2004. http://dx.doi.org/10.1016/j.nucengdes.2007.11.011

Matsuo, E., Abe, Y., Iwasawa, Y., Ebihara, K., Koyama, K., 2015. Numerical simulation of jet breakup behavior by the lattice Boltzmann method. Trans. JSME 81, 1-20. http://dx.doi.org/10.1299/transjsme.14-00409

McCarthy, M.J., Molloy, N.A., 1974. Review of stability of liquid jets and the influence of nozzle design. Chem. Eng. J. 7, 1-20. http://dx.doi.org/10.1016/0300-9467(74)80021-3

McKinley, G.H., Renardy, M., 2011. Wolfgang von Ohnesorge. Phys. Fluids 23, 127101. $\underline{\text { http://dx.doi.org/10.1063/1.3663616 }}$

Meister, B.J., Scheele, G.F., 1969a. Drop formation from cylindrical jets in immiscible liquid systems. AIChE J. 15, 700-706. http://dx.doi.org/10.1002/aic.690150513

Meister, B.J., Scheele, G.F., 1969b. Prediction of jet length in immiscible liquid systems. AIChE J. 15, 689-699. http://dx.doi.org/10.1002/aic.690150512

Merrington, A.C., Richardson, E.G., 1947. The break-up of liquid jets. Proc. Phys. Soc. 59, 1-13. http://dx.doi.org/10.1088/0959-5309/59/1/302

Milosevic, I.N., Longmire, E.K., 2002. Pinch-off modes and satellite formation in liquid/liquid jet systems. Int. J. Multiphase Flow 28, 1853-1869. http://dx.doi.org/10.1016/S0301-9322(02)00046-0

Moriyama, K., Maruyama, Y., Usami, T., Nakamura, H., 2005. Coarse break-up of a stream of oxide and steel melt in a water pool. JAERI-Research 2005-017, Japan Atomic Energy Research Institute.

Nishimura, S., Sugiyama, K., Kinoshita, I., Itagaki, W., Ueda, N., 2010. Fragmentation mechanisms of a single molten copper jet penetrating a sodium pool—transition from thermal to hydrodynamic fragmentation in instantaneous contact interface temperatures below its freezing point-. J. Nucl. Sci. Technol. 47, 219-228. http://dx.doi.org/10.1080/18811248.2010.9711948

Ohnesorge, W. v., 1936. Die Bildung von Tropfen an Düsen und die Auflösung flüssiger Strahlen. J. Appl. Math. Mech. 16, 355-358. http://dx.doi.org/10.1002/zamm.19360160611

Pilch, M., Erdman, C.A., 1987. Use of breakup time data and velocity history data to predict the maximum size of stable fragments for acceleration-induced breakup of a liquid drop. Int. J. Multiphase Flow 13, 741-757. 


\section{Manuscript for Nuclear Engineering and Design}

\section{http://dx.doi.org/10.1016/0301-9322(87)90063-2}

Pillai, D.S., Vignesh, R., Sudha, A.J., Pushpavanam, S., Sundararajan, T., Nashine, B.K., Selvaraj, P., 2016. Experimental simulation of fragmentation and stratification of core debris on the core catcher of a fast breeder reactor. Nucl. Eng. Des. 301, 39-48. http://dx.doi.org/10.1016/j.nucengdes.2016.02.038

Rayleigh, Lord, 1878. On the instability of jets. Proc. London Math. Soc. s1-10, 4-13. http://dx.doi.org/10.1112/plms/s1-10.1.4

Riestenberg, D., Chiu, E., Gborigi, M., Liang, L., West, O.R., Tsouris, C., 2004. Investigation of jet breakup and droplet size distribution of liquid $\mathrm{CO}_{2}$ and water systems-implications for $\mathrm{CO}_{2}$ hydrate formation for ocean carbon sequestration. Am. Mineral. 89, 1240-1246. http://dx.doi.org/10.2138/am-2004-8-911

Saito, M., Sato, K., Imahori, S., 1988. Experimental Study on Penetration Behaviors of Water Jet into Freon-11 and Liquid Nitrogen, in: ANL Proceedings: National Heat Transfer Conference. Houston, USA, pp. 173-183.

Saito, R., Abe, Y., Yoshida, H., 2014. Experimental study on breakup and fragmentation behavior of molten material jet in complicated structure of BWR lower plenum. J. Nucl. Sci. Technol. 51, 64-76. http://dx.doi.org/10.1080/00223131.2014.849211

Saito, R., Abe, Y., Yoshida, H., 2016. Breakup and fragmentation behavior of molten material jet in multi-channel of BWR lower plenum. J. Nucl. Sci. Technol. 53, 147-160. http://dx.doi.org/10.1080/00223131.2015.1027756

Saito, S., Abe, Y., Kaneko, A., Iwasawa, Y., Matsuo, E., Ebihara, K.-I., Sakaba, H., Koyama, K., Nariai, H., 2014a. Influence of hydrodynamic interaction on jet breakup and fragmentation behavior, in: 22nd International Conference on Nuclear Engineering. Prague, Czech. http://dx.doi.org/10.1115/ICONE22-30028

Saito, S., Abe, Y., Kaneko, A., Kanagawa, T., Iwasawa, Y., Matsuo, E., Ebihara, K., Sakaba, H., Koyama, K., Nariai, H., 2014b. Visualization and measurement of jet breakup behavior with interfacial fragmentation using LIF and PIV, in: 9th Korea-Japan Symposium on Nuclear Thermal Hydraulics and Safety. Buyeo, Korea, N9P0025.

Saito, S., Abe, Y., Kaneko, A., Kanagawa, T., Iwasawa, Y., Matsuo, E., Ebihara, K., Sakaba, H., Koyama, K., Nariai, H., 2015a. Experimental study on jet instability and breakup behavior in liquid-liquid system, in: 23rd International Conference on Nuclear Engineering,. Chiba, Japan, ICONE23-1886

Saito, S., Abe, Y., Koyama, K., 2015b. Visualization and measurement of jet breakup behavior using LIF. Trans. JSME 81, 15-00395. http://dx.doi.org/10.1299/transjsme.15-00395

Saito, S., Abe, Y., Kaneko, A., Kanagawa, T., Iwasawa, Y., Koyama, K., 2016a. Simulation of a liquid jet using the lattice Boltzmann model for immiscible two-phase flow. Jpn. J. Multiphase Flow 29, 433-441. http://dx.doi.org/10.3811/jjmf.29.433

Saito, S., Iwasawa, Y., Abe, Y., Kaneko, A., Kanagawa, T., Nariai, H., Koyama, K., 2016b. Jet breakup and droplet formation in immiscible liquid-liquid system, in: 24th International Conference on Nuclear Engineering. Charlotte, USA, p. V004T13A010. http://dx.doi.org/10.1115/ICONE24-60634

Schins, H., Gunnerson, F.S., 1986. Boiling and fragmentation behaviour during fuel-sodium interactions. Nucl. Eng. Des. 91, 221-235. http://dx.doi.org/10.1016/0029-5493(86)90077-4

Spencer, B.W., Gabor, J.D., Cassulo, J.C., 1986. Effect of boiling regime on melt stream breakup in water, in: 4th 


\section{Manuscript for Nuclear Engineering and Design}

Miami International Symposium on Multi-Phase Transport \& Particulate Phenomena. Miami Beach, USA.

Spencer, B.W., Wang, K., Blomquist, C.A., McUmber, L.M., Schneider, J.P., 1994. Fragmentation and quench behavior of corium melt streams in water, NUREG/CR-6133, ANL-93/32. http://dx.doi.org/10.2172/10136350

Suzuki, T., Kamiyama, K., Yamano, H., Kubo, S., Tobita, Y., Nakai, R., Koyama, K., 2014a. A scenario of core disruptive accident for Japan sodium-cooled fast reactor to achieve in-vessel retention. J. Nucl. Sci. Technol. 51, 493-513. http://dx.doi.org/10.1080/00223131.2013.877405

Suzuki, T., Yoshida, H., Nagase, F., 2014b. Development of numerical evaluation method for fluid dynamics effects on jet breakup phenomena in BWR lower plenum. J. Nucl. Sci. Technol. 51, 968-976. http://dx.doi.org/10.1080/00223131.2014.924447

Takahashi, T., Kitamura, Y., 1971. Laminar breakup length of a liquid jet in another immiscible liquid -dispersion of denser liquid-. Chem. Eng. 35, 637-643. http://dx.doi.org/10.1252/kakoronbunshu1953.35.637

Takahashi, T., Kitamura, Y., 1972. Laminar breakup length of a liquid jet in another immiscible liquid -dispersion of lighter liquid-. Chem. Eng. 36, 912-916. http://dx.doi.org/10.1252/kakoronbunshu1953.36.912

Tanasawa, Y., Toyoda, S., 1954. A study on the atomization of high speed liquid jets (2nd report). Trans. Jpn. Soc. Mech. Eng. 20, 306-309. http://dx.doi.org/10.1299/kikai1938.20.306

Tang, L., Masutani, S.M., 2003. Laminar to turbulent flow liquid-liquid jet instability and breakup, in: 13th International Offshore and Polar Engineering Conference. pp. 317-324.

Thakre, S., Manickam, L., Ma, W., 2015. A numerical simulation of jet breakup in melt coolant interactions. Ann. Nucl. Energy 80, 467-475. http://dx.doi.org/10.1016/j.anucene.2015.02.038

Tomotika, S., 1935. On the instability of a cylindrical thread of a viscous liquid surrounded by another viscous fluid. Proc. R. Soc. A Math. Phys. Eng. Sci. 150, 322-337. http://dx.doi.org/10.1098/rspa.1935.0104

Wei, H., Erkan, N., Okamoto, K., 2016. Experimental investigation of the effect of control rod guide tubes on the breakup of a molten metal jet in the lower plenum of a boiling water reactor under isothermal conditions. J. Vis. http://dx.doi.org/10.1007/s12650-016-0390-6 